\title{
LA INTERPRETACION E INTEGRACION DE LAS LAGUNAS DE LA CONVENCION DE VIENA DE 1980: LOS PRINCIPIOS EN QUE SE INSPIRA Y LOS PRINCIPIOS «UNIDROIT»
}

\author{
Javier San Juan Crucelaegui \\ Doctor en Derecho. Profesor en la Universidad de Deusto
}

Sumario: Introducción. I. La necesidad de uniformidad en la interpretación de un texto internacional y en la integración de sus lagunas. II. La relevancia de los Principios generales en que la Convención se inspira para la integración de sus lagunas: cuestiones sistemáticas previas. 1. La necesaria presencia en la Convención de principios generales subyacentes a la misma. 2. Las pautas para la identificación de los Principios generales. III. La especial relevancia del Principio de buena fe en la interpretación de la Convención y en la integración de sus lagunas. 1. La problemática recepción del principio de buena fe en la Convención de Viena. 2. El Principio de buena fe en la interpretación del contrato. A. El Principio de buena fe en los sistemas del Common Law. B. El Principio de buena fe en los sistemas de inspiración civilista. C. El Principio de buena fe en la Convención. IV. La identificación de otros Principios generales subyacentes a la Convención. 1. El principio de buena fe y sus implicaciones. 2. Los principios generales relativos a la concepción del contrato. 3. Principios relativos a las obligaciones de las partes. 4. Principios relativos a los derechos de las partes. 5. Principios relativos a la transmisión del riesgo. 6. Principios relativos al cómputo de los plazos contractuales. 7. Principios relativos al pago del precio. V. La utilización de los Principios UNIDROIT para la integración de la Convención de Viena de 1980. 1. La posibilidad de la interpretación e integración de la Convención de Viena mediante la utilización de los Principios UNIDROIT. 2. Los supuestos de dificultad en la coordinación entre la Convención de Viena y los Principios UNIDROIT. A. Las diferencias apreciables entre las regulaciones de ambos textos. B. La determinación de la preeminencia entre ambos textos. 3. La utilización de los Principios UNIDROIT por los Tribunales internos. 4. La Convención de Viena y los Principios UNIDROIT en el arbitraje de derecho. 5. La Convención y los Principios UNIDROIT en el arbitraje de equidad. 


\section{Introducción}

El art. 7 de la Convención de Viena de 1980 (CV) contempla dos cuestiones de índole general. La primera de ellas es cuestión tradicional, común a cualquier texto jurídico, relativa a los problemas que pudiera presentar la interpretación del texto y la significación precisa del mismo. En lo relativo a tal cuestión, dicho precepto pone de relieve - como no podía ser de otra manera- la necesidad de un especial énfasis en la necesidad de proporcionar impulso a la uniformidad de su interpretación potencialmente universal para, a continuación y a tal objeto, hacer expresa referencia a la observancia y propagación del principio de buena fe.

La segunda pone de manifiesto un mayor grado de complejidad, y es la relativa a la definición de los criterios a utilizar para colmar las lagunas de que el texto pudiera resentirse. Para ello, la CV contiene una mención secundaria al recurso a los criterios de un ordenamiento jurídico interno, aquél cuya aplicabilidad resultare declarada por la norma de conflicto. Tal criterio resulta de clara inadecuación conceptual cuando se trata de un texto internacional (transnacional), de aplicación potencialmente universal. En consecuencia, la auténtica y veraz respuesta o solución radicará en la definición o inducción de aquellos principios generales en los que la Convención se inspira y que subyacen a la misma.

\section{La necesidad de uniformidad en la interpretación de un texto internacional y en la integración de sus lagunas}

Los criterios para la interpretación de la CV consisten, en primer lugar, en la consideración de su carácter internacional de lo que deriva la necesidad de uniformidad en su interpretación potencialmente universal, ajena, por tanto, a los criterios hermenéuticos de los sistemas jurídicos internos; en segundo lugar, la interpretación de la Convención debe ser guiada por la observancia del principio de buena fe ${ }^{1}$. Lo bus-

\footnotetext{
1 Sobre la interpretación de la Convención, vid. ADAME GODDARD, Reglas de interpretación de la Convención sobre compraventa internacional de mercaderías, en «Diritto del Commerzio Internazionale», 1990, págs. 103 y sigs.; Bonell, La Convenzione di Viena sulla vendita internazionale: origini, scelte e principi fondamentali, en «Rivista Trimestrale di Diritto e Procedura Civile», 1990, págs. 727 y sigs.; EöRsI, A Propos the Viena Convention for the International Sale of Goods, en «American Journal of Comparative Law», 1983, págs. 349 y sigs.; FerRARI, Interpretation Uniforme de la Convention de Vienne de 1980 sur la Vente Internationale, en «Revue Internationale de Droit Comparé», 1996, n. ${ }^{4}$,
} 
cado consiste en la evitación de la aplicación a la Convención de los criterios de interpretación pertenecientes a un ordenamiento jurídico que, por su particularismo ${ }^{2}$, habrán de resultar generalmente inadecuados para la hermenéutica de un texto de origen y aplicación internacionales, pretendiéndose, pues, la preservación de la uniformidad en la interpretación y aplicación de la Convención ${ }^{3}$.

págs. 814-852; PeRAles VisCASILlas, Una aproximación al art. 7 de la Convención de Viena 1980 sobre compraventa internacional de mercaderías, en «Cuadernos de Derecho y Comercio», n. ${ }^{\circ} 16,1995$, págs. 55 y sigs; SAN JuAn CRUCELAEGui, La aplicación e interpretación de la Convención de Viena de las Naciones Unidas sobre compraventa internacional de mercaderías, en «Estudios de Deusto», Vol. 51/2, 2003, págs. 195-231.

${ }^{2}$ Resulta de extrema importancia que la Convención reciba una interpretación homogénea por parte de los tribunales de los diferentes países signatarios, por lo que los fallos jurisprudenciales pronunciados por los tribunales de cada país no pueden resultar indiferentes a los demás. En lo que a jurisprudencia sobre la Convención se refiere, vid. BonelL, Rasegna giurisprudenziale in tema di vendita internazionale, en «Diritto del Commerzio Internazionale», 1993, 1994, 1995, 1996; FERRARI, Specific Topics of the CISG in the Light of Judicial Application and Scholarly Writing, en «Journal of Law and Commerce», 1995; FERRARI, La compraventa internacional: aplicabilidad y aplicaciones de la Convención de Viena de 1980, Valencia, Tirant lo blanch, 1999, págs. 327-332; PiLtZ, La Convención de Viena de 1980 de Compraventa Internacional de Mercaderías en la jurisprudencia internacional, en «La Ley», 1992-3, págs. 942 y sigs; VÁzQUEZ LEPINETE, Primera jurisprudencia sobre la Convención de Viena, en «Rev. General de Derecho», 1996, págs. 3437 y sigs; WILL, International Sales Law under CISG. The UN Convention on Contract for the International Sale of Goods. The First Hundred Decisions, en «Cahiers des Etudiants Allemands en Droit a Genève», Ginebra, 1994, reproducido en «Review of the Convention on Contracts for the International Sale of Goods», 1995; del mismo autor, The UN Convention on Contracts for the International Sale of Goods. International Bibliography 1980-1995. The First 150 or so Decisions 1988-1995, Ginebra, 1996; del mismo autor, The First 464 or so decisions, Ginebra, 1998; WITZ, Les premieres applications jurisprudentielles du droit uniforme de la vente internationale (Convention des Nations Unies du 11 avril 1980), París, LGDJ, 1995.

${ }^{3}$ Los fallos jurisprudenciales y arbitrales sobre la Convención sobrepasan ya el millar de decisiones. Además de las publicaciones de jurisprudencia mencionadas a lo largo del presente trabajo, en particular su Sección 2. a, existen diversas bases de datos en las que es posible encontrar referencias de gran amplitud. Son las siguientes:

1) CISG W3, Base de datos del Institute of International Comercial Law, Universidad de Pace (White Plains-New York), dirigida por KRITZER y TrifFIN, accesible en www.cisg.law.pace.edu

2) UNILEX, International Case Law and Bibliography on the UN Convention on Contracts for the International Sale of Goods, del «Centro di Studi e Richerche di Diritto Comparato e straniero», Roma, dirigido por Bonell, accessible en www.unilex.info.

3) CLOUT, Case Law on Uncitral Texts, accessible en www.uncitral.org.

4) UNIDROIT, Base de datos del Instituto Internacional para la unificación del Derecho Privado, Roma, accesible en www.UNIDROIT.org.

5) CISG, España y Latinoamérica, BD de la Universidad Carlos III de Madrid, dirigida por Illescas Ortiz y Perales Viscasillas, accesible en www.uc3m.es/cisg. 
La consideración de la internacionalidad esencial de la Convención trae consigo la proscripción de los criterios interpretativos propios de los ordenamientos jurídicos internos de lo que debe seguirse, consecuentemente, una aplicación hermenéutica desvinculada del significado propio y tradicional de los términos de los ordenamientos internos. Por tanto, en la interpretación de la Convención de Viena es preciso desvincularse de conceptos particulares que sean privativos de un determinado ordenamiento jurídico ${ }^{4}$. Ello se pone más claramente de manifiesto si se tiene en cuenta que la Convención es igualmente auténtica en seis idiomas, lo que conduce inexorablemente a evitar una interpretación de cada uno de sus términos no sólo según las diferentes lenguas, sino también en función del significado propio que les otorgan los diferentes ordenamientos jurídicos nacionales ${ }^{5}$.

Es distinto el caso de aquellos conceptos típicos de determinado ordenamiento jurídico interno que, sin embargo, han sido adoptados como propios por la Convención para la construcción de su propio y específico andamiaje conceptual, lo que sucede en mayor medida con conceptos procedentes de los sistemas anglosajones aun cuando también se depare cabida, aun cuando en menor grado, a conceptos e instituciones procedentes de los ordenamientos de inspiración civilista. Siendo tal el caso, parece claro que la correcta interpretación de los términos y conceptos de la Convención llevará a la utilización de los desarrollos y criterios interpretativos que se hubieren producido en el ámbito jurídico de procedencia de tal concepto o institución ${ }^{6}$.

En cuanto a la integración de las lagunas de un texto internacional, de aplicación potencialmente universal, se ha señalado, fundadamente, que una de las carencias del derecho internacional uniforme se encuentra, precisamente, en la propia naturaleza de las cosas. Los procesos de unificación jurídica no pueden comenzar con una codificación general del Derecho civil, ni tan siquiera del Derecho de obligaciones. Proyec-

${ }^{4}$ La afirmación es de FerRari, La compraventa internacional... cit., pág. 31.

5 Cfr. Illescas Ortiz y Perales Viscasillas: Derecho Mercantil Internacional. El Derecho Uniforme, Madrid, Centro de Estudios Ramón Areces, 2003, pág. 118.

6 Vid., VAN DER VELDEN, Indications of the Interpretation by Dutch Courts of the United Nations Convention on Contracts for the International Sale of Goods, en «Netherlands Reports to the Tweelfth Congress of Comparative Law: Sidney-Melbourne 1986», págs. 33 y sigs, para quien «en caso de que la fuente de una disposición de derecho uniforme pueda identificarse en un derecho nacional, este derecho nacional lógicamente constituye un instrumento de ayuda en la interpretación de las disposiciones de derecho uniforme»; en igual sentido, MANN, Uniform Statutes in English Law, en «Law Quaterley Review», 1983, pág. 383. 
tos de esta índole requerirían inmensos esfuerzos y, probablemente, seguirían siendo una utopía. Si el derecho debe ser aceptado, lo que resulta aún más evidente en el derecho internacional unificado que en el nacional, tiene que estar fundamentado en convicciones jurídicas que deben ser compartidas por la mayoría de los destinatarios de dicho derecho. Teniendo en cuenta las diferencias sociales, económicas, políticas e ideológicas que diferencian a los Estados y que influyen en áreas jurídicas sensibles (por ejemplo, el derecho de protección de los consumidores), no es fácil hablar de convicciones fundamentales comunes ya existentes. Por tanto, la unificación jurídica entre varios Estados tiene que producirse a propósito de cuestiones más concretas y parciales. Así, por ejemplo, el esperado Code des Obligations, de 1929, con el que se pretendió la unificación de los derechos de obligaciones francés e italiano nunca llegó a ver la luz. Incluso, a pesar de la estrecha colaboración legislativa existente entre los países del norte de Europa, no pudo llevarse a cabo una codificación general de amplias materias jurídicas sino, únicamente, leyes singulares como las leyes sobre la compraventa. La promulgación del Uniform Commercial Code (UCC) de los EE.UU. hubiera sido probablemente imposible sin sus precedentes como la Uniform Sales Act de 1906.

Por otra parte, unido a la realización de los procesos de unificación se encuentra un cierto carácter fragmentario de la regulación. Incluso en convenciones de amplia repercusión como la Convención de Viena, en la que se ha querido regular de manera extensa las relaciones contractuales entre las partes de la compraventa, quedan sin resolver cuestiones sobre el derecho general de obligaciones, por lo que su coordinación con un sistema legal nacional resulta problemática.

Las afirmaciones anteriores arrastran la consecuencia de la necesidad o conveniencia del establecimiento de principios generales rectores de las actividades mercantiles internacionales que, además, pudieran coadyuvar a la interpretación de textos asimismo internacionales. Por ello, junto a la definición e inducción de los principios generales que inspiran y subyacen a la Convención, se ha de tomar en consideración que el Instituto para la Unificación del Derecho Privado (UNIDROIT), con sede en Roma, ha publicado «Los Principios para los Contratos Comerciales Internacionales» (PCCI), texto que recoge y contempla los principios de aplicación a la generalidad de tipos y categorías contractuales y, por lo mismo, también al contrato de compraventa internacional de mercaderías, por lo que dichos Principios UNIDROIT podrían resultar complementarios de los principios generales subyacentes a la Convención de Viena de 1980. 


\section{La relevancia de los Principios generales en que la Convención se inspira para la integración de sus lagunas: cuestiones sistemáticas previas}

La integración de las lagunas de que el texto de la CV pudiera resentirse es lo contemplado en el art. 7. 2 de la Convención, a cuyo tenor «las cuestiones relativas a las materias que se rigen por la presente Convención que no estén expresamente resueltas en ella se dirimirán de conformidad con los principios generales en que se basa la presente Convención o, a falta de tales principios, de conformidad con la ley aplicable en virtud de las normas de derecho internacional privado».

El citado precepto, que ostenta especial relevancia en el ámbito de la Convención, es consecuencia de la reacción suscitada por la incertidumbre que anteriormente se había derivado del art. 17 de la LUCI, de forma que el art. 7 (2) de la Convención vino a constituir un compromiso entre quienes temían que los tribunales experimentaran una querencia que les llevara a una precipitada y prematura utilización del ordenamiento interno de aplicación, a quienes iba dedicada la mención a los principios generales y, de otro lado, aquellos que dudaban de que los principios generales pudieran ser precisados, en atención a los cuales el citado precepto finalizó con la inclusión de la remisión a un sistema interno por el intermedio de la norma de conflicto ${ }^{7}$.

Sin embargo, a pesar de la literalidad del art. 7. 2 de la Convención, antes de recurrir a la aplicación de alguno de los principios generales en que aquélla se fundamenta e inspira, es preciso hacer mención, en primer lugar, del recurso a la analogía ${ }^{8}$, tras lo cual corresponderá el recurso a los principios generales subyacentes a la Convención para, en último lugar, a falta tanto de orientación fundamentada en la analogía como de principios generales, el art. 7. $2 \mathrm{CV}$ permite el recurso a los criterios integradores de aquel ordenamiento interno cuya aplicación fuera reclamada por la norma de conflicto ${ }^{9}$. El precepto pretende dis-

7 Cfr. En particular BiANCA y BonEll (coords.): Commentary on the International Sales Law. The 1980 Vienna Sales Convention, Milán, Giuffré, 1987. Colaboraciones, entre otros, de Barrera Graf, Bianca, Bonell, Evans, Farnsworth, Kayme, Knapp, Maskow, NichOlas, RAisky, RoNDino, SONÓ, TALlon, Will, pág. 78.

8 Para ello será necesario el cumplimiento de un doble requisito pues, en un primer momento, será necesaria la identificación de la norma rectora de un supuesto semejante al carente de regulación, para analizar, a continuación, la similitud entre el caso efectivamente previsto por la norma y las características del caso que se trata de resolver. Cfr., en particular, BonELL, en BiAnCA y Bonell (coords.), Commentary on the International Sales Law, cit. pág. 78.

${ }^{9}$ La inclusión del art. 7 II en la Convención fue muy controvertida, habiendo quedado expresamente excluido durante las deliberaciones iniciales. También en la Conferencia di- 
tanciar a la Convención de la orientación anteriormente seguida por la LUCI $^{10}$, la cual impedía el recurso al sistema conflictual para la interpretación e integración de sus lagunas, lo que constituyó una de las razones del parco éxito registrado por el citado texto uniforme internacional. Redacción parecida a la del art. 7 II de la Convención ya había sido incluida en el art. 11 del primer borrador de la Ley Unificada sobre Compraventa, de 1935, según el cual, «caso de que la presente Ley no regule de forma expresa un supuesto y no se hubiera previsto la aplicación de un derecho nacional, el Tribunal deberá decidir de acuerdo con los principios generales por los que se rige esta Ley» ${ }^{11}$.

La pauta inspiradora del art. 7. 2 de la Convención ha sido seguida por otras convenciones internacionales posteriores. Constituye así elemento esencial de las disposiciones generales de esta clase de convenciones. Aun tomando en consideración lo anterior, el precepto ha sido objeto de intensas críticas doctrinales ${ }^{12}$ pues, de un lado, transmite una impresión de rechazo frente a la aplicabilidad de criterios internos y, de otro lado, determina su aplicabilidad a falta de principios generales inspiradores de la Convención. Además, puede señalarse que entra en fricción con el criterio del art. 7. 1 que señala como criterio interpretativo de la misma la necesidad de promover la uniformidad en su aplicación, lo que difícilmente puede ser conseguido por recurso a los criterios de

plomática de 1980, este precepto fue muy discutido. La redacción actual se basó en una propuesta de compromiso de Alemania que unió principios generales y Derecho Internacional Privado, logrando una ajustada mayoría.

${ }^{10}$ Cfr. Defranco y Dore, A comparison of the non-substantive provisions of the $U N$ CITRAL convention on the international sale of goods and the UCC, en «Harward International Law Journal», 1982, pág. 63.

${ }^{11}$ El citado precepto fue interpretado en el sentido de que establece el principio general para la integración de las lagunas del texto. Dado que los jueces pertenecen a sistemas jurídicos diferentes y están acostumbrados a aplicar derechos distintos, el peligro para el mantenimiento de un ámbito jurídico realmente único reside en la existencia de interpretaciones jurídicas divergentes, pues existe el riesgo de que los Tribunales, para llenar las lagunas, apliquen su ordenamiento jurídico interno, con lo que desaparecería la deseada unidad jurídica. Sin embargo, los fundamentos unitarios de decisión son absolutamente imprescindibles. Por ello. dicho precepto establece que los conflictos no expresamente regulados por la Ley también queden sometidos a la misma, debiendo ser resueltos de acuerdo con el espíritu que emana de los principios de la Ley. Estos principios son calificados como generales, en expresión que recuerda al art. 38 del Estatuto del Tribunal Permanente de La Haya y que hace referencia, como fuente de derecho, a los elementos comunes de los conceptos jurídicos que deben ser hallados por comparación de los sistemas jurídicos. Cfr. RABEL, The Hague Conference on the Unification of Sales Law, en «The American Journal of Comparative Law», 1952, págs. 58-69.

12 Cfr. KAHN, La Convention de Vienne du 11 avril 1980: caracteres et domaine d'application, en «Droit et Pratique du Commerce Internationale», 1989, págs. 397-398. 
los ordenamientos internos entre los que, frecuentemente, se impone la apreciación de diferencias y discrepancias.

En consecuencia, es de señalar que tales consideraciones y, singularmente, la propia literalidad del art. 7 de la CV, pese a sus imprecisiones y contradicciones, implican que el sistema conflictual puede ser, únicamente, utilizado con carácter residual para la integración de las lagunas de que pudiera resentirse el texto de la Convención.

La apreciación de la existencia de lagunas en la Convención dependerá, en buena medida, de la propia interpretación que se dispense a sus disposiciones. En cualquier caso, la integración de las lagunas de que la Convención pudiera finalmente resentirse en cuestiones que, aun regidas por la Convención, no se hallaren expresamente resueltas en ella, debe tomar en consideración el recurso a los propios principios generales en que se basa la Convención como principal criterio integratorio del texto. La definición o inducción de aquellos principios generales inspiradores de un texto internacional, a los que éste obedece y se sujeta, resulta de decisiva relevancia pues es altamente improbable que la redacción y literalidad de un texto internacional resulten perfectamente completas en sí mismas.

Cuando la Convención careciere de norma de expresa aplicación y la analogía tampoco proporcionare criterios que permitieran colmar el silencio del texto, procederá la integración de tal laguna mediante la utilización de los principios que subyacen a la Convención y en los cuales ésta se inspira. De acuerdo con la exposición de Honnold ${ }^{13}$, una respuesta mesurada a la invitación de la Convención a la aplicación de principios generales, con anterioridad a la utilización de un ordenamiento interno, puede suavizar la confusión inherente al sistema conflictual y ayudar a evitar la aplicación no crítica y torpe del Derecho extranjero. Tal concepción del art. 7.2 puede ayudar, a través de la casuística y de la doctrina, a la creación de un derecho uniforme de acuerdo con las circunstancias cambiantes. El problema, sin embargo, estriba en que la Convención no enumera tales principios, por lo que doctrina y jurisprudencia han intentado la identificación y precisión de los principios generales sobre los que la Convención se estructura.

Pese a las afirmaciones anteriores y, quizá, como consecuencia de las mismas, el establecimiento de principios generales rectores de las actividades mercantiles internacionales que, además, pudieran coadyuvar a la interpretación de textos asimismo internacionales, puede resultar de extrema importancia. En este sentido, caben determinadas re-

13 Ibidem, pág. 154. 
flexiones acerca del art. 7 de la Convención que, asimismo, podrían ser igualmente extendidas a disposiciones similares recogidas en convenciones sobre otros contratos como los de representación, leasing o factoring.

\section{La necesaria presencia en la Convención de principios generales subyacentes a la misma}

Caso de que, en el proceso de aplicación de la Convención, resultare necesario el recurso a los principios generales mencionados en su art. 7 II, será necesaria la previa certeza en el sentido de que la cuestión planteada afecta a una materia regulada por la Convención, aun cuando no expresamente resuelta por la misma (laguna interna).

Dejando a un lado los supuestos expresamente excluidos de la Convención (vgr. la transmisión de la propiedad), en ocasiones resulta difícil trazar la línea divisoria entre las materias reguladas y excluidas de la Convención. Tal es el problema en lo relativo a la inclusión o exclusión de las reclamaciones precontractuales, a la regulación de la compensación, aun de forma parcial, o a la regulación de la carga de la prueba. La identificación o inducción de principios jurídicos de carácter general, suficientemente ciertos, extraídos de la propia Convención, contribuiría a la aplicación más homogénea de la Convención. La finalidad del art. 7 de la Convención, así como de determinados preceptos de otras convenciones unificadoras del derecho privado más recientes, es garantizar dicha aplicación.

Por el contrario, la posibilidad de aplicación de principios generales ajenos a la Convención resulta difícil y dudosa. Así, de acuerdo con el texto y antecedentes del art. 7 de la Convención, no resulta posible el recurso a los principios jurídicos generales reconocidos por los Estados a los que hace referencia el art. 38 del Estatuto del Tribunal Internacional. A pesar de que tal idea inspiró en cierta medida el borrador de 1935, la misma no fue aplicada íntegramente. El texto del art. 7 II de la Convención únicamente permite la aplicación de aquellos principios que supongan basamento para la Convención (como se recoge en la preponderante versión inglesa, mientras que la versión francesa, menos restrictiva, hace referencia a los principios «en los que se inspire»). En consecuencia, la Convención deberá indicar, o de la misma se deberá poder deducir con la suficiente certeza, que un determinado principio general le subyace. Sin tal vinculación al texto y a la estructura de la Convención, la aplicación de principios generales resultaría aleatoria, poniéndose en serio riesgo el objetivo de homogeneidad de la interpretación.

Por lo mismo, en términos generales, tampoco resulta posible la posibilidad de integración de lagunas mediante la identificación, para ca- 
sos concretos, de principios comunes por comparación entre los ordenamientos jurídicos de los Estados firmantes de la Convención. En este caso, también faltaría el nexo entre los principios así obtenidos y la Convención, así como, probablemente, una verdadera aceptación general de dichos principios. Por otra parte, una comparación intensiva de diversos sistemas jurídicos con el fin de obtener un principio general para un caso concreto supondría un esfuerzo excesivo para el agente aplicador del derecho, por lo que, en muchas ocasiones, prevalecería la tendencia a entender como correcta la solución dada al caso concreto por el ordenamiento interno propio. Un planteamiento de este tipo no puede servir a la unidad interpretativa y de aplicación de la Convención.

En conclusión y en principio, el art. 7 II de la Convención se limita a aquellos principios generales que forman la base de la Convención, que la han inspirado y respecto de los cuales la propia Convención contiene puntos de referencia, por lo que resulta dudoso el recurso a principios generales ajenos a la Convención.

Sin embargo, podría ser conveniente dispensar una consideración especial, incluso con rango de excepción a la afirmación anterior, a aquellos casos en que se hubieran desarrollado principios básicos de carácter general que hubieran sido aprobados internacionalmente y gozaran de aceptación general ${ }^{14}$. Aunque inicialmente la Convención no se haya basado en estos principios, no parece se deba excluir radicalmente el recurso a tal método de desarrollo. De esta forma se podría combatir la tantas veces criticada «fosilización» del Derecho uniforme. Aún así, debería ser condición previa la aceptación internacional de los principios generales así creados.

\section{Las pautas para la identificación de los principios generales}

De la Convención de Viena (y de otras convenciones de derecho uniforme) se pueden extraer principios generales mediante distintas consideraciones.

14 La referencia lo es a la codificación de los principios generales de la contratación internacional preparada por UNIDROIT. Vid. BoELe-WoelKI, Principles and Private International Law: the UNIDROIT Principles and the Principles of European Contract Law: How to Apply Them to International Contracts, en «Uniform Law Review», 1996, págs. 652 y sigs. Más adelante se examinará con mayor detenimiento el grado en que los Principles of International Commercial Contracts desarrollados por UNIDROIT cumplen con este requisito. Sobre el intento de consecución de una codificación europea al respecto, vid. Díez Picazo, Roca Trías y Morales, Los Principios del Derecho Europeo de Contratos, Madrid, Civitas, 2002. 
Por un lado, algunas disposiciones de la Convención reclaman su aplicación a todo el cuerpo legal, tales como el art. 6 (principio de la autonomía de las partes), el art. 7 I (principio de buena fe), o el art. 11 (principio de libertad de forma). Su carácter de norma general se desprende de su contenido y de su posición sistemática al hallarse incluidos entre las «Disposiciones generales» de la Convención. En sentido estricto, no deberían ser considerados entre los principios generales aludidos en el art. 7 II, al exteriorizar de forma clara su aplicación general, no siendo por tanto principios que «se encuentren ocultos en la ley... sin gozar de una expresión directa». Sin embargo, como consecuencia de su capital importancia que, a veces, excede su tenor literal, resulta adecuada su inclusión entre los principios generales de la Convención.

Por otra parte, otros principios de tipo general pueden ser extraídos de diferentes disposiciones concretas. Así, los arts. 67 II y 69 II de la Convención establecen que la transmisión del riesgo presupone la puesta a disposición de la mercancía, principio que puede resultar generalizable a aquellos casos en los que la cuestión, como sucede con el contenido del art. 68, no esté expresamente regulada.

Además, cabe considerar que otras disposiciones concretas contienen criterios jurídicos susceptibles de generalización que pueden ser aplicados a cuestiones análogas. El art. 20 II de la Convención puede servir como ejemplo. Según esta norma, los días festivos no prorrogan los plazos de aceptación salvo que la entrega no hubiera sido posible por causa de tal festividad. Este criterio puede ser generalizado en el sentido de entender que todos los plazos incluyen los días festivos (por ejemplo, también para las entregas), salvo que la correspondiente actuación (por ejemplo, la entrega) no pudiera ser llevada a cabo debido a un día festivo. En tal caso el plazo se prorrogaría consecuentemente.

Finalmente, del contexto general cabe inferir la existencia de algún principio general, aun cuando el mismo no resulte expresamente citado. A título de ejemplo, en tal sentido, cabe la mención de la regla pacta sunt servanda, principio no mencionado en ningún precepto de la Convención que, sin embargo, constituye el fundamento de la regla de excepción del art. 79 que establece el momento en que un deudor se libera de su obligación.

En cuanto a las pautas sistemáticas para la identificación de tales principios generales ${ }^{15}$, pueden mencionarse las siguientes:

15 Cfr. Honnold, Uniform Law for International Sales under the 1980 United Nations Convention, 3. ${ }^{\mathrm{a}}$ ed., Deventer/Boston, Kluwer, 1999, págs. 152 y sigs. 
1) El primer paso debe consistir en el examen de los supuestos regulados expresamente por las disposiciones de la Convención.

2) El segundo paso implica la formulación de alguna de las dos conclusiones siguientes consistentes en que, (i) o bien la redacción de la Convención ha rechazado deliberadamente la regulación de cuestiones determinadas y, por ende, la inclusión de determinadas disposiciones, o bien (ii) que la carencia de una disposición específica para la regulación del problema en cuestión resulta de un fallo para anticipar y resolver esta cuestión.

3) El tercer paso, en el supuesto de que se hubiera colegido la última conclusión, consistiría en considerar si la comparación entre aquellos casos efectivamente regulados por las disposiciones de la Convención con el caso en cuestión arroja tal grado de analogía que un legislador no habría elegido deliberadamente unos resultados discordantes para un pluralidad de situaciones similares. En este caso, parece apropiado concluir que el principio general que abarque estas situaciones está comprendido en el art. 7. 2 de la Convención. Por tanto, el método incluye la aplicación analógica de las disposiciones específicas de la Convención.

\section{La especial relevancia del Principio de buena fe en la interpretación de la Convención y en la integración de sus lagunas}

La observancia de la buena fe en el comercio internacional es principio de interpretación de la Convención, que establece como finalidad general de interpretación la obligación de aseguramiento de la observancia de la buena fe en el comercio internacional. Con ello, el art. 7 trata de evitar el recurso prematuro a un ordenamiento interno.

\section{La problemática recepción del principio de buena fe en la Convención de Viena}

Sin embargo, la recepción del principio de buena fe en la Convención, así como el alcance y significado del principio, es cuestión objeto de opiniones diferentes, lo que resulta ser consecuencia de que la Convención hace mención del principio de buena fe exclusivamente en lo atinente a la interpretación de su propio texto por lo que, tomado el art. 7, 1 en su literalidad, tal función interpretativa es la única respaldada por el citado precepto y, por lo mismo, es disposición substancialmente dirigida a jueces y árbitros llamados a la práctica interpretativa de la Convención. 
El citado precepto ha sido objeto de comentarios críticos y apelativos tales como que se trata de «un desafortunado compromiso» ${ }^{16}$, «previsión ciertamente peculiar» ${ }^{17}$ o, no sin una cierta ironía, «compromiso propio de hombres de estado» ${ }^{18}$ que no entraña la imposición a las partes del contrato de un deber de buena fe. La turbulenta historia de la preparación de la Convención pone de manifiesto que la introducción del principio constituyó un compromiso de difícil construcción. Mientras algunos países eran favorables a su introducción, otros argumentaron que contenía un mandato demasiado impreciso en relación a lo requerido por un conflicto internacional, que tendría que ser cumplido por los jueces, por lo que hicieron patente su oposición a cualquier referencia general al principio de buena fe. De resultas de ello y de la cierta ambigüedad del texto, son diversas las posturas doctrinales sobre el alcance del principio de buena fe en la Convención.

Para una primera dirección doctrinal, la Convención debe ser interpretada desde su estricta literalidad, lo que llevaría a colegir que el principio no estaría contemplado en la Convención. A ello cabría adjuntar la consideración de que tampoco podría ser extraído de los principios generales en que se fundamenta la Convención. Y aún cabría argumentar que podría constituir auténtica perversión dar cabida a un principio general de buena fe por la puerta de atrás ${ }^{19}$.

Para un segundo grupo de autores, la Convención, interpretada asimismo desde su más estricta literalidad y al igual que en el supuesto anterior, no abarcaría al principio de buena fe. Sin embargo, podría considerarse que dicho principio podría ser extraído de los principios generales en que la Convención se fundamenta. En tal caso, tal deber de conducta sería exigible a las partes con el contenido y significado que un juez podría entender contemplado por la Convención. Esta lectura de la Convención podría fundamentarse en la consideración de que un cierto número de preceptos que hacen concreta referencia a la buena fe constituyen particular aplicación de dicho principio, por lo que ca-

16 Cfr. Carbonneau y Firestone, Transnational Law Making: Assesing the Impact of the Vienna Convention and the Viability of National Adjudication, en «Emory Journal International», 1986, pág. 51. Los citados autores utilizan la expresión «an awkward compromise».

17 Cfr. Bonell, Commentary on the International Sales Law: The Vienna Sales Convention, art. 7, Milán, Giuffré, 1987, n. ${ }^{\circ} 2.4$.

18 Cfr. Farnsworth, Problems of Unification of Sales Law from Standpoint of the Common Law Countries, 1980, pág. 19, quien usa la expresión «a statesmanlike compromise».

19 Cfr. Farnsworth, Duties of Good Faith and Fear Dealing... cit. pág. 55. 
bría sostener que la buena fe es uno de los principios generales en que se fundamenta la Convención en su conjunto ${ }^{20}$.

Para una última línea doctrinal, puede realizarse una más amplia lectura de la Convención, marginando su estricta literalidad, con lo que cabría la conclusión de que la previsión que impone al juez la observancia de la buena fe en la interpretación de la Convención, impondría igualmente tal deber de buena fe a la conducta de las partes. Otros autores, aun reconociendo que la literalidad de la Convención no impone a las partes un deber de adecuación de su conducta a la buena fe, insisten en la afirmación de la existencia de tal obligación ${ }^{21}$.

En suma, en términos generales y de conformidad con el art. 7 de la Convención, la regla de la buena fe sólo es aplicable a la interpretación de las disposiciones de la Convención aun cuando, de acuerdo con la opinión mayoritaria, dicho principio también debe servir de guía para la interpretación del contrato en concreto, así como para la totalidad de las relaciones jurídicas existentes entre las partes.

Sin embargo, para que el principio pueda servir de efectiva ayuda al juez en un caso concreto, debe ser objeto de mayor precisión. En este sentido, es mayoritaria la opinión en el sentido de que del art. 7 I se deduce la prohibición del abuso de derecho, así como la invocación de actos propios contradictorios (venire contra factum propium). Ambas concreciones del principio aparecen igualmente recogidas en otros preceptos de la Convención. Así, por ejemplo, el art. 29 II 2 impide el abuso de una posición jurídica formal. Con carácter más general, se deduce del art. 80 que una parte no podrá obtener ventaja de un comportamiento propio infractor de un deber. Como ejemplos de un venire contra factum propium sancionados, cabe citar el art. 16 II b (irrevocabilidad de una oferta cuando el oferente haya creado una situación de confianza), y el art. 50 II (exclusión de la rebaja cuando el acreedor rechace injustificadamente un cumplimiento posterior). Adicionalmente, del art. 7 I de la Convención se puede deducir que las partes están obligadas a actuar en el comercio internacional de conformidad con las pautas y criterios de un ordenado comerciante, aun cuando también podría considerarse que un principio de este tipo parece excesivamente

20 Cfr. Bonell, Commentary on the International Sales Law, cit. n. ${ }^{\text {o }}$ 2. 4. 1.

21 En tal sentido vid. FARnsworTh, Duties of Good Faith and Fear Dealing... cit. pág. 56; sosteniendo igual opinión y sobre las negociaciones acerca de la inclusión del principio de buena fe en la Convención y las dificultades y discusiones suscitadas al respecto, cfr. EÖRSI, A propos the 1980 Vienna Convention on Contracts for the International Sale of Goods, en «American Journal of Comparative Law», 1983, vol. 31, n. ${ }^{\circ}$ 2, págs. 348-349; la misma idea es respaldada por IllesCas OrTIZ y Perales Viscasillas, Derecho Mercantil Internacional, cit. pág. 118. 
indeterminado. Cuando en el sector de actividad concreto existan usos internacionales, los mismos deberán ser observados de conformidad con el art. 9 de la Convención. Pero un principio general de estas características podría entrañar el riesgo de que el juzgador, a la hora de tomar una decisión, aplicase sus estándares nacionales propios.

En todo caso, la formulación de una conclusión debe tomar inexcusablemente en consideración la expresa mención del art. 7. 1 de la Convención a la necesidad del aseguramiento de la buena fe en el comercio internacional. Es cierto que el citado precepto se refiere únicamente a los criterios de aplicación a la interpretación de la Convención, pero no es menos cierto que lo protegido por el precepto es la observancia y propagación de la buena fe en el comercio internacional. Tal formulación, aun indirecta, obliga a considerar que el principio de buena fe constituye expreso criterio hermenéutico de la Convención pues, de otro modo, ésta no podría cumplir con la misión que le viene atribuida.

A esta consideración cabe añadir que, en cualquier caso, el principio constituye inspiración general y básica de la Convención inducible, como tal, desde diversos preceptos de la misma. Junto a lo anterior, se debe considerar que el principio de buena fe ha sido concebido tradicionalmente como criterio de interpretación contractual por lo que, siendo tal su misión primordial, no parece pueda quedar al margen de los criterios inspiradores o hermenéuticos aplicables al texto regulador del contrato que debe ser asimismo objeto de interpretación. En suma, parece procedente la conclusión de que la observancia de la buena fe en el comercio internacional es principio de interpretación tanto de la Convención como del propio contrato de compraventa internacional de mercaderías. Tal conclusión parece ser la igualmente respaldada en mayor medida por la jurisprudencia ${ }^{22}$.

\section{El principio de buena fe en la interpretación del contrato}

La interpretación de la voluntad de las partes del contrato es lo regulado en el art. 8 de la Convención relativo a los actos y declaraciones de las partes. Sin embargo, aun cuando el principio de buena fe no se encuentre expresamente mencionado en el art. 8 de la Convención en cuanto específico criterio de interpretación de los términos del contrato, su consideración como principio general inspirador de la Convención hace que resulte, asimismo, de aplicación a la cuestión.

22 En particular, St. Cour d'Appel de Grenoble, de 22 de febrero de 1995, caso SARL Bri Production Bonaventure c. Societé Pan Africa Export, en «Journal de Droit International», 1995, págs. 639 y sigs., CLOUT n. ${ }^{\circ} 154$. 
El principio de buena fe aplicado al contrato hace referencia, generalmente, a la conducta del hombre en su relación jurídica con los demás, en donde se tiene en cuenta, más que sus móviles internos de carácter psíquico, su obrar conforme a las reglas normales y aceptadas de la honestidad y de la rectitud. Constituye regla de conducta exigible, según los criterios morales y sociales dominantes ${ }^{23}$. La bona fides ha sido considerada siempre como de necesaria observancia en la vida humana de relación, y forma parte de los principios jurídicos fundamentales, del honeste vivere ${ }^{24}$.

La buena fe resulta ser principio informador de un sistema jurídico que halla su aplicación a través de la interpretación e integración de las normas, así como de la suplencia de éstas y de la interpretación de los contratos y demás negocios jurídicos. La buena fe es, además, concepto básico para determinar el ejercicio normal o abusivo de los derechos ya que hay evidente conexión entre mala fe y abuso. Es, asimismo, postulado básico por cuanto representa una de las más fecundas vías de irrupción del contenido ético-social en el orden jurídico. Por su generalidad el precepto adolece de una natural vaguedad en cuanto a su formulación, y en cada caso concreto en que haya de aplicarse habrá que considerar lo que por conducta normal, recta y honesta se entiende. Esta conducta habrá de ser apreciada por la comúnmente seguida por un hombre corriente, hombre medio, lo que tradicionalmente se ha llamado un buen padre de familia, en función de la circunstancia de que se trate ${ }^{25}$. No busca la definición del patrón de hombre ideal, tal cual debería ser, sino el patrón del hombre corriente, tal cual es, en un momento histórico determinado ${ }^{26}$.

23 Por lo que al Derecho español se refiere, la buena fe es invocada por los arts. 1.258 CC y 57 Cco. a propósito del cumplimiento de los contratos. En nuestro sistema, además de la acepción indicada, la expresión buena fe puede ostentar una doble significación, pues, con ella, también se hace referencia a la creencia y consiguiente intención de los sujetos de derecho (art. $433 \mathrm{CC}$ ).

24 Cfr. Batlle, en Albaladejo García y Díaz Alabart (Dirs), Comentarios al Código Civil y Compilaciones Forales, Tomo I, Madrid, Edersa, 1993, págs. 78 y sigs, quien reproduce la máxima de Ulpiano: iuris praecepta sunt haec: honeste vivere, alterum non leadere, suum cuique tribuere.

25 Entre otras, vid. STS, de 3 de abril de 1968, que indica de modo claro su carácter de «principio general de nuestro sistema jurídico» y precisa que «consiste en el respeto a las normas de conducta colectiva que son propias de toda conciencia honrada y leal y van implícitamente exigidas en cada caso como necesarias para el normal y feliz término de todo negocio jurídico».

${ }_{26}$ Una aplicación concreta del principio resulta ser la de que «nadie puede ir contra sus propios actos», variando sin causa justificada lo que él mismo estableció por actos concretos y a través de su conducta, defraudando con ello la confianza de los demás basada en la natural consecuencia de las diversas acciones de una persona, inspiradas por una línea di- 
En relación a la recepción del principio de buena fe en la convención, surgen dos cuestiones producto de las diferentes concepciones de los diversos sistemas jurídicos: $1 .^{\mathrm{a}}$ ) la primera de ellas, anteriormente expuesta, hace referencia a la propia recepción del principio en la Convención, lo que ha dado pie a opiniones encontradas, siendo posible afirmar, en los momentos actuales, su aceptación generalizada; $2 .^{a}$ ) por ello, la segunda cuestión consiste en la precisión de su alcance y significado en un texto internacional ante las diferencias que, sobre el mismo, pudieran apreciarse entre los ordenamientos internos para lo que es necesario el análisis de los pronunciamientos de los diversos sistemas jurídicos.

\section{A) El PRINCIPIO DE BUENA FE EN LOS SISTEMAS DEL «COMMON LAW»}

El principio de buena fe, en los países del Common Law, no encontró su origen en el derecho británico, fuente tradicional de las nociones generales o básicas del Commnon Law, sino en el derecho de los EEUU pues, aun cuando es cierto que, ya en 1766, Lord Mansfield se había referido a la buena fe como «un principio rector... aplicable a todos los contratos ${ }^{27}$ ), dicho principio nunca arraigó en Gran Bretaña ${ }^{28}$. El principio ha suscitado interés, recientemente, en los ámbitos jurídicos británicos y, en tal sentido, el Lord of Justice Steyn ${ }^{29}$ sostuvo, en 1991, que, como consecuencia de la carencia del principio de buena fe, el derecho inglés debía servirse de la doctrina de la implication of terms. Por ello, la atención se debería centrar en el propósito del contrato o, lo que es lo mismo, la promoción de la good faith and fair dealing.

El principio fue retomado en los EEUU con ocasión de la preparación del Uniform Commercial Code (UCC), inspirado en el principio Treu und Glauben del art. 242 del $\mathrm{BGB}^{30}$, momento a partir del cual el principio de buena fe alcanzó preeminencia significativa. Bajo la in-

rectriz que se revela a los otros por los propios actos de aquélla. Al respecto, vid. STS de 17 de mayo de 1941 y 11 de octubre de 1966.

27 Pronunciamiento recaído en el caso Carter vs. Boehm, 97, «English Rep». 1162, 1164, KB. 1766.

28 Vid. Cheshire, Fifoot \& Furmston's, Law of Contract, 1991, pág. 141.

29 Cfr. STEYn, The Role of Good Faith and Fair Dealing in Contract Law, a Hair Shirt Philosophy, 1991; DenNing L.J. 131, pág. 133. Sobre el principio de buena fe en los sistemas anglosajones, vid. en general, FARNSwORTH, Duties of Good Faith and Fear Dealing under the UNIDROIT Principles, Relevant International Conventions and National Laws, en «Tulane Journal of International and Comparative Law», 1995, vol. 3, págs. 47 y sigs.

30 Art. 242 BGB. «El deudor está obligado a efectuar la prestación de acuerdo a los requisitos de la fidelidad y buena fe, teniendo en consideración los usos del tráfico». Cfr. EIRanova Encinas, Código Civil Alemán, Barcelona, Marcial Pons, 1998. 
fluencia del UCC, los redactores del Restatament (Second) of Contracts añadieron una previsión según la cual todo contrato impone a cada una de las partes del mismo, en lo relativo a sus derechos y obligaciones, $a$ duty of good faith and fair dealing ${ }^{31}$. En lo relativo a la cuestión, los tribunales de EEUU han aplicado diferentes definiciones de la noción de buena fe para la justificación de aquellos pronunciamientos fundamentados en tal doctrina:

1. El criterio más restrictivo acerca del significado del principio expresa $^{32}$ que la buena fe es simplemente un nuevo bautizo de los principios fundamentales del derecho contractual, de forma que el significado del principio resulta equivalente al significado de la doctrina implying terms of the agreement.

2. Para una segunda concepción ${ }^{33}$, el criterio de la buena fe es noción que no contiene significación general en sí misma, aun cuando es criterio de exclusión pues sirve como fundamento para la exclusión de diversas formas de mala $\mathrm{fe}^{34}$.

3..$^{\circ}$ En tiempos más recientes ${ }^{35}$, se ha propuesto una tercera definición del principio, para la cual la buena fe implica una limitación en el grado de discrecionalidad en el cumplimiento de las obligaciones contractuales, aun cuando tal discrecionalidad hubiera sido otorgada en el contrato en favor de una sola de las partes. En consecuencia, constituye mala fe la búsqueda de ventajas adicionales en el cumplimiento del contrato, o la renuencia a la asunción de los costes que entraña el cumplimiento del contrato.

La jurisprudencia de los EEUU ha utilizado estas tres concepciones al objeto de la definición del principio de buena fe, con frecuencia sin distinguir apropiadamente entre ellas, lo que no es tan sorprendente

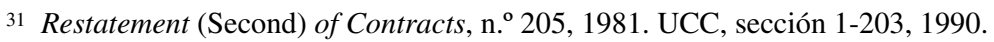

32 Pronunciamiento del Juez ScAlia, caso Tymeshare vs. Covell, Fed. 2d, 1145, 1152, DC, Cir. 1984. Sobre el principio ente los tribunales de EEUU, vid. FARnSwOrTh, art. cit. págs. 47-63.

33 Cfr. el influyente estudio de Summers, «Good Faith» in General Contract Law and the Sales Provisions of the Uniform Commercial Code, en «Harvard Law Rev.», 1968, págs. 195 y sigs.

34 A ello responde el Restatament (second) of contracts, n. ${ }^{\circ} 205$, cmt. D: «a complete catalogue of types of bath faith is impossible, but the following types are among those which have been recognized in judicial decisions: evasion of the spirit of the bargain, lack of diligence and slacking off, wilful rendering of imperfect performance, abuse of a power to specify terms, and interference with or failure to cooperate in the other party's performance».

35 Cfr. Burton, Breach of Contract and the Common Law Duty to Perform in Good Faith, en «Harvard Law Rev.», 1980, 94, pág. 369. 
puesto que la significación del principio puede variar en función de las circunstancias del caso, y lo apropiado de cada una de tales definiciones puede depender de la función que el principio está llamado a servir.

B) EL PRINCIPIO DE BUENA FE EN LOS SISTEMAS DE INSPIRACIÓN CIVILISTA

En la generalidad de los ordenamientos jurídicos de inspiración civilista que, en términos generales, tienen mayor tradición en lo relativo al principio de buena fe que los pertenecientes al Common Law, el citado principio ostenta una triple funcionalidad ${ }^{36}$ :

1. ${ }^{a}$ En primer lugar, los contratos deben ser interpretados de acuerdo con la buena fe de modo que, si las intenciones de las partes no aparecieran reflejadas con claridad, el contrato debe ser interpretado de acuerdo con aquel significado que le hubieran dado unas partes razonables, y no precisamente de acuerdo con los términos literales del contrato.

2. ${ }^{a}$ En segundo lugar, el principio de buena fe tiene una función complementaria, de manera que determinados derechos y obligaciones podrían afectar a las partes, aun no hallándose expresamente recogidos en el contrato. Esta función es equivalente a la doctrina de la implication of terms anglosajona.

3. ${ }^{a}$ Por último, la buena fe ostenta una función derogadora o restrictiva, de manera que una norma obligatoria para las partes, aun contenida en el texto del contrato, no se aplica si el resultado de su aplicación resultara contrario a la buena fe. Esta función restrictiva del principio ha inspirado pronunciamientos diversos, tales como la adaptación del contrato a unas circunstancias cambiantes, la revisión de las cláusulas del contrato que no fueren racionales, o la regla del venire contra factum propium.

La distinción entre estas diversas funciones no siempre resulta clara y, más en especial, puede resultar dificultosa la distinción entre la función interpretativa y la función complementaria, o la distinción entre esta última y la restrictiva. Se hubiera podido esperar que los ordenamientos de la Europa continental hubieran especificado con mayor claridad las funciones del principio de buena fe reconocidas en los diferentes sistemas, pero no es tal el caso.

36 Cfr. Hartkamp, The Concept of Good Faith in the UNIDROIT Principles for International Commercial Contracts, en «Tulane Journal of International and Comparative Law», 1995, vol. 3, págs. 65 y sigs. 
Aun así, todos los sistemas aceptan la función de la buena fe en la interpretación de los contratos. Así lo hacen el código alemán y el italiano ${ }^{37}$, aun cuando los códigos francés, belga o el holandés no contienen tal expresa manifestación ${ }^{38}$. A su vez, la función complementaria del principio de buena fe está recogida en los códigos civiles francés, italiano y holandés, pero no lo está en el código alemán ni en el código suizo, aun cuando es también aceptada en estos sistemas ${ }^{39}$.

Finalmente, la función restrictiva del principio de buena fe resulta ser la más problemática. El único código civil que la recoge expresamente es el nuevo código civil holandés de $1992^{40}$, que estatuye que una obligación que recae sobre las partes derivada de un contrato no se aplica en la medida en que, bajo ciertas circunstancias, pudiera resultar inaceptable de acuerdo con los criterios de razonabilidad y equidad, expresiones éstas últimas que resultan equivalentes a la anglosajona good faith and fair dealing ${ }^{41}$.

En otros países, la función restrictiva del principio de buena fe surge de la interpretación de la noción hecha por los pronunciamientos jurisprudenciales, ante la redacción un tanto imprecisa de los pronunciamientos legales. Así, el Código Civil suizo ${ }^{42}$ simplemente establece que las partes deben ejercitar sus derechos y cumplir con sus obligaciones de acuerdo con la buena fe. De forma parecida, el BGB estatuye que el deudor está obligado a cumplir su prestación de acuerdo con los requisitos de fidelidad y buena fe pero, en paralelo y según lo establecido por la jurisprudencia, el acreedor puede esgrimir su derecho si no fuere contrario a la buena fe.

En suma, la función restrictiva del principio de buena fe únicamente recibe formulación legal de manera excepcional, aun cuando reciba general respaldo jurisprudencial.

\section{C) El principio de buena fe en la Convención}

La concepción substancialmente similar del principio de buena fe en los distintos ordenamientos jurídicos internos incluye las tres funciones anteriormente aludidas, y lleva a la consideración de que dichas funciones son, asimismo, las contenidas en el principio de buena fe de

37 Art. 157 BGB, y art. 1366 del Codice Civile.

38 Art. 1134 del Code Civil, y art. 6. 2 del «Nieuw Burgerluk Wetboek» (Nuevo Código Civil de Holanda) NBW.

39 Cfr. HARTKAMP, art. cit. págs. 66-68.

40 «Nieuw Burgerluk Wetboek», (NBW), art. 6. 2.

41 Cfr. HARTKAMP, art. cit. pág. 68.

${ }^{42}$ Code des Obligations (ZGB), art. 2, 1. 
la Convención. Los propios términos de la Convención, con la constante mención a estándares de razonabilidad en relación a las más diversas circunstancias y comportamientos, constituyen otro argumento en sí mismos. A ello mismo apunta el art. 1.7 de los Principios UNIDROIT para los contratos mercantiles internacionales al que se atribuye este igual significado, pues no resulta convincente que un mismo concepto ostente contenido distinto en diferentes textos internacionales ${ }^{43}$.

Por el contrario, señala Farnsworth que los juristas pertenecientes a los sistemas civilistas consideran el principio de buena fe como esencial componente de sus respectivos sistemas legales, mientras que los juristas de sistemas pertenecientes al Common Law lo consideran como una reciente innovación producida en sus sistemas.

En síntesis de lo anterior, cabe afirmar que la Convención no ha tenido éxito en su intento de definición y efectiva incorporación de la doctrina de la buena fe sino que, únicamente, ha incluido un desafortunado e inviable compromiso entre los sistemas civilistas y los opuestos puntos de vista de los sistemas del Common Law.

En cualquier caso, el principio de buena fe deberá ser tomado en consideración en la preparación y elaboración de los términos del contrato, pues impone un deber de claridad en su redacción y la marginación de expresiones deliberadamente confusas en busca de ventajas adicionales que la otra parte pudiera no advertir. La consecuencia adicional del principio, según la exposición de Díez Picazo ${ }^{44}$, implica la interpretación de las declaraciones de las partes de acuerdo con el grado de confianza que hubieran causado, de lo que se sigue la aplicación de la regla de la interpretatio contra stipulatorem para la fijación del significado de aquellas cláusulas que se resintieran de obscuridad, pues no favorecer al causante de la obscuridad quiere decir favorecer a su adversario. Por otra parte, el principio fundamenta una interpretación del contrato que favorezca la normal ejecución de las obligaciones contractuales en el marco de las reglas de la justicia y de la ética.

La aplicación del principio de buena fe a los contratos internacionales tendrá gran influencia en la consecución de resultados satisfactorios. Sin embargo, el principio debe ser aplicado con un adecuado grado de restricción. En el campo del comercio internacional, las partes

43 Cfr. Farnsworth, Duties of Good Faith and Fear Dealing, cit. págs. 59 y sigs.

${ }^{44}$ Cfr. Díez Picazo, Fundamentos del Derecho Civil Patrimonial, Madrid, Tecnos, 1993, Tomo I, pág. 372, «...pues hay en dicho principio un fin de protección de intereses impuesto por la buena fe: no favorecer al causante de la oscuridad quiere decir favorecer a su adversario». 
del contrato están normalmente en situación de establecer los términos de su relación. Por tanto, las partes deben poder confiar en los términos por ellas mismas elegidos. Sólo cuando tal confianza conlleve un resultado no razonable (tomando en consideración la naturaleza y finalidad del contrato y otras circunstancias relevantes) sería procedente que un juez o un árbitro procedieran a complementar, modificar o restringir cualesquiera de los contenidos del contrato ${ }^{45}$.

\section{La identificación de otros Principios generales subyacentes a la Convención}

A pesar de la significativa relevancia de los principios subyacentes a la Convención, los pronunciamientos jurisprudenciales al respecto, judiciales o arbitrales, son escasos y han llegado a parcas conclusiones ${ }^{46}$. Por su parte, un sector de la doctrina entiende que de la Conven-

45 Cfr. HartKamp, The Concept of Good Faith... cit, pág. 71.

46 Entre los pronunciamientos jurisprudenciales de mayor relevancia cabe citar los siguientes:

1. El principio de que la resolución del contrato de compraventa no afecta a a las cláusulas compromisorias que se hubieran pactado. Cfr. St. del caso Finalto Spa. vs. Chilewich International Corpque que estableció «...contracts and the arbitration clauses included therein are considered to be «severable», a rule that the Convention itself adopts with respect to avoidance of contracts generally».

2. ${ }^{\circ}$ La prohibición del venire contra factum propium (ex. arts. 7.2; 16.2 (b); y 29. 2).

3. ${ }^{\circ}$ El de que las partes, en una relación que se prolonga a lo largo del tiempo, tienen obligación de comunicarse entre ellas (46).St. del US District Court, Southern District of New York, de 14 abril de 1992, caso Filanto Spa. vs. Chilewich International Corp., CLOUT, núm. 23. Se ha afirmado al respecto que «...The opinion may... be read as saying that the parties in a long-term relationship owe to each other a duty to communicate, a duty which ultimately may be derived from a duty to act in good faith». Cfr. WINSHIP, The UN Sales Convention and the Emerging Case Law, en NeumaYer (coord.), Emptio-Venditio Internationales. Basilea, 1997, pág. 228.

4..$^{\circ}$ El principio de que la carga de la prueba de los defectos de las mercaderías y de su denuncia en plazo corresponde a quien los alega (arts. 38 y 39) (46). Cfr. St. del Handelsgericht de Zurich, 9 de septiembre de 1993, CLOUT, núm. 97.

5. ${ }^{\circ}$ El principio consistente en que el perjudicado por un incumplimiento contractual deber ser reintegrado por la totalidad de los daños patrimoniales sufridos (arts. 74 y 78) (46). Cfr. Laudo arbitral de la Cámara Federal de Comercio de Viena, 15 junio de 1994, CLOUT, núm. 93.

6. ${ }^{\circ}$ El principio de que todos los pagos derivados de la Convención (incluso los indemnizatorios) deben hacerse, en defecto de pacto, en el domicilio del acreedor (art. 57.1 (a) (46)); Cfr. St. del OLG de Dusseldorf, de 2 julio de 1993, CLOUT, núm. 49. 
ción sólo se pueden extraer algunos principios generales. Sin embargo ${ }^{47}$, se han establecido catálogos de mayor amplitud ${ }^{48}$, definiendo posibles principios generales ${ }^{49}$ distintos en cada caso $^{50}$. En términos generales, dichos catálogos coinciden con aquellos principios que conforman el contenido de una lex mercatoria internacional ${ }^{51}$.

$7^{\circ}$ ) El principio de que, en defecto de pacto sobre la divisa en que haya de hacerse el pago, ésta será la del lugar de pago (arts. 54 y 78).

8. ${ }^{\circ}$ Finalmente, el principio de que los intereses adeudados, en defecto de pacto, son los del país en cuya divisa se pactó el pago del precio (46). Cfr. Laudo Arbitral de la Cámara Húngara de Comercio e Industria, de 5 de diciembre de 1995, CLOUT, n. ${ }^{\circ} 164$.

47 El primero fue propuesto por HonNOLD, quien identifica entre tales principios inspiradores de la Convención: $1^{\circ} .^{\text {) }}$ la confianza en las manifestaciones de la otra parte (pacta sunt servanda o estoppel); $2^{\circ}$ ) la obligación de comunicar la información que la otra parte necesita (con fundamento en los arts $19,21,26,39,65) ; 3 .^{\circ}$ ) el principio de que una parte debe procurar evitar el deterioro de las mercaderías, evitando así daños innecesarios a la otra parte, incluso en el supuesto de que la otra parte hubiera enviado una mercadería defectuosa o incurrido en cualquier otro incumplimiento del contrato (mitigation). Cfr. Uniform Law...cit. págs. 160 y sigs.

48 Posteriormente, AudiT añadió a los citados: $1^{\circ}$ ) el principio del favor negotii que busca la preservación de la vigencia del contrato y no su resolución (con fundamento en los arts. 25, 26, 34, 37, 47, 48, 49, 63, 64); 2. ${ }^{\circ}$ ) la obligación de las partes de cooperar de buena fe con independencia de las estipulaciones concretas (arts. 32, 60); $3 .^{\circ}$ ) la consideración de la razonabilidad de una conducta o actuación, criterio ampliamente presente en la Convención, consistente en aquello que haría una persona normalmente diligente, que se hallara en circunstancias similares (con fundamento en los arts. 18, 33, 38, 39, 43, 47, 49, $63,64,65,72,73,75) ; 5 .^{\circ}$ ) el principio de que una parte no puede incurrir en contradicción con declaraciones o comportamientos que hubieren resultado decisivos para que la otra parte adaptara su conducta a tales declaraciones y comportamientos (arts. 16, 29, 47, 63). Cfr. La vente internationale de marchandises, cit. págs 50 y sigs.

49 Por su parte, FERRARI distingue entre las lagunas de la Convención intra legem (o materias que la Convención no ha deseado contemplar) y lagunas extra legem (lagunas auténticas, producto de silencios o errores de la Convención). Partiendo de una comparación entre los principios generales de los ordenamientos civilistas y del Common Law, el citado autor infiere determinados principios subyacentes a la Convención e inspiradores de la misma. Cfr. Interpretation Uniforme de la Convention de Vienne cit. págs. 843 y sigs.

${ }_{50}$ Más reciente, Magnus, Die allgemeinen Grundsätze im UN-Kaufrecht, en «Rabels Zeitschrift für ausländisches und internationales Privatrecht», 1995, págs. 470 y sigs., sistematiza un amplio listado de principios generales de la Convención; VÁZQUEZ LEPINETE, Compraventa Internacional de Mercaderías, cit. págs. 50 y sigs., y las referencias jurisprudenciales allí mencionadas; Illescas Ortiz y Perales Viscasillas, Derecho Mercantil Internacional cit. pág. 119.

51 Asimismo, SAN JuAn Crucelaegui, La aplicación e interpretación de la Convención de Viena de las Naciones Unidas sobre compraventa internacional de mercaderías, en «Estudios de Deusto», Vol. 51/2, 2003, págs. 195-231. 


\section{El principio de buena fe y sus implicaciones}

En cuanto a los principios generales o subyacentes a la Convención, en primer lugar, cabe hacer mención del principio de buena fe, anteriormente mencionado, objeto de expresa mención por parte de la Convención la cual lo eleva al rango de principio esencial en el desarrollo del comercio internacional. Junto a tal principio, cabe hacer mención de los siguientes:

1. $\left.{ }^{\circ}\right)$ El principio pacta sunt servanda. El principio básico según el cual los contratos son vinculantes no está expresamente recogido en la Convención. Sin embargo, es presupuesto de forma implícita por diversos preceptos como, por ejemplo, los arts. 30 y 53 de la Convención que regulan las obligaciones de entrega de la mercancía y pago del precio. Asimismo, los arts. 71 a 73 y 79 señalan que una relación contractual no se extinguirá por simple alteración de las circunstancias, la desaparición del objeto del negocio o situaciones similares, sino sólo cuando concurran los requisitos recogidos en estos preceptos. Sin el carácter vinculante del contrato, esta regulación carecería de sentido ${ }^{52}$.

2. $\left.{ }^{\circ}\right)$ La protección de la confianza inducida. En estrecha relación con el principio de la buena fe, se encuentra el principio según el cual la parte que hubiera inducido una determinada situación de confianza, que hubiere sido determinante para la actuación de la otra parte, deberá quedar vinculada por la situación creada. El art. 16 II (b) y el art. 29 II (2), ambos anteriormente mencionados, así como el art. 35 II (b) (confianza en la competencia específica del vendedor) y el art. 42 II (b) (ausencia de responsabilidad por vicios en caso de que el vendedor al fabricar la mercancía se hubiera ajustado a las especificaciones facilitadas por el comprador) indican que subyace a la Convención un concepto jurídico general aplicable a situaciones análogas. Así, por ejemplo, un vendedor no podrá rechazar la reclamación por vicios formulada por un comprador cuando él mismo haya causado la impresión y el comprador hubiera confiado en que el vendedor aceptaría y solventaría la reclamación (por ejemplo, hecha de forma demasiado genérica). Asimismo, en caso de que una de las partes genere la apariencia de estar dispuesta a aceptar cambios en las condiciones del contrato, deberá quedar vinculada por la misma siempre que la otra parte ya hubiera actuado basándose en dicha apariencia.

52 La resolución del contrato de compraventa no afecta a las cláusulas compromisorias que se hubieran pactado (52). St. Flnalto Spa. vs. Chilewich International Corpque que estableció «...contracts and the arbitration clauses included therein are considered to be "severable", a rule that the Convention itself adopts with respect to avoidance of contracts generally». 
Se desdibuja así el límite respecto de aquellos supuestos en que es de aplicación la prohibición del venire contra factum proprium. Sin embargo, sólo puede apelar a la protección de la confianza quien realmente hubiera confiado en determinado comportamiento de la otra parte. Por el contrario, la prohibición del venire contra factum proprium no presupone una situación de confianza.

3. $\left.{ }^{\circ}\right)$ El principio de la razonabilidad o adecuación de la conducta de las partes. Distintos preceptos de la Convención se fundamentan en el concepto de razonabilidad (reasonable, raisonable). En unos casos, el concepto se refiere a plazos que deben ser razonables (art. 39 I) $\mathrm{y}$, en otros, se hace alusión al comportamiento de una parte que debe ser razonable o adecuado. En ambos casos será de aplicación el principio general del art. 8 de la Convención, que obliga a aplicar con carácter general un criterio objetivo tomando como base el comportamiento de una ordenada persona media o normal que actuase en una situación análoga, aun cuando habrán de tenerse en cuenta las circunstancias excepcionales que deban ser tomadas en consideración (art. 8 III), así como los usos internacionales (art. 9).

4..$^{\circ}$ La caducidad de los derechos y pretensiones contractuales. El principio de buena fe está estrechamente relacionado con el concepto de caducidad de los derechos y pretensiones contractuales.

Aun cuando no resulta plenamente pacífico, podría afirmarse que se puede extraer un principio de la Convención, compartido por diversos ordenamientos jurídicos internos, consistente en que la falta de ejercicio de sus derechos por una de las partes durante cierto período de tiempo, creando así la apariencia frente al obligado de que no es su intención el ejercicio de determinado derecho o pretensión contractual, puede entrañar la caducidad de tal derecho o pretensión. Este principio puede ser deducido de aquellos pasajes de la Convención que reflejan el principio de la protección de la confianza. De esta forma, podría excluirse el recurso a la regulación de la caducidad contenida en el ordenamiento interno invocado por la norma de conflicto.

Los arts. 46 y 47 de la Convención pueden constituir plasmación o ejemplo de lo anterior al establecer plazos y condiciones para la exigencia de cumplimiento por el comprador. Consecuentemente, el comprador podrá dejar caducar su derecho a la entrega.

\section{Los principios generales relativos a la concepción del contrato}

5..$\left.^{\circ}\right)$ La primacía de la voluntad de las partes. Los acuerdos entre partes gozan de preferencia sobre las disposiciones de la Conven- 
ción (art. 6), criterio respaldado de manera unánime por los pronunciamientos doctrinales y jurisprudenciales. La libertad de decisión de las partes es prácticamente ilimitada, si bien con algunas excepciones recogidas en el art. 12 de la Convención (exigencia de forma), en el art. 4, a de la Convención relativo a la cuestión de validez del contrato de compraventa, lo que deberá ser resuelto de acuerdo con un ordenamiento interno y mediante la aplicación del principio de buena fe (art. 7 I de la Convención). En consecuencia, la Convención únicamente será de aplicación respecto de aquellas cuestiones no reguladas por las partes.

6..$^{\circ}$ La libertad de forma del contrato. El art. 11 de la Convención sanciona el principio de la libertad de forma en relación a la conclusión del contrato y su prueba, para el caso de que un estado ratificante de la misma no hubiera hecho uso de la reserva de forma del art. 96 en relación con el art. 12. Es decir, de dicho precepto se deriva el principio general de que, de acuerdo con la Convención, las declaraciones de cualquier tipo, como reclamaciones por vicios, declaraciones de rescisión, etc., no están sometidas a forma determinada.

7. $\left.{ }^{\circ}\right)$ La primacía de los usos del comercio internacional. Entre los principios generales e indiscutidos de la Convención se encuentra el de la observancia de los usos internacionales de comercio (art. 9). Los usos que fueran ampliamente conocidos en el comercio internacional, reguladores de determinado sector de actividad, pueden (más allá del texto del art. 9 de la Convención) ser utilizados para la resolución de problemas de interpretación de la propia Convención. Sin embargo, esta posibilidad cabría únicamente en aquellos casos en que se cumplieran las condiciones que, de conformidad con el art. 9, permiten la aplicación de los usos internacionales, es decir, su reconocimiento internacional y la regularidad de su observancia.

8..$^{\circ}$ El principio del favor negotii. Diversos preceptos permiten deducir que la Convención sólo permite la resolución de un contrato cuando concurran determinados requisitos y, además, como última medida (arts. 25, 34, 37, 47, 48, 49, 63 y 64). Lo que se pretende, siempre que sea posible, es evitar la resolución del contrato de compraventa en atención a sus negativas consecuencias económicas. Sólo en aquellos casos en que la gravedad del incumplimiento contractual no sea soportable, la parte perjudicada deberá tener la posibilidad de resolver el contrato. Este principio también debería ser aplicable a aquellos casos en que se incumplan obligaciones no expresamente reguladas por la Convención o a aquellas obligaciones a las que las partes hayan hecho extensiva la Convención. 


\section{Principios relativos a las obligaciones de las partes}

9. $\left.{ }^{\circ}\right)$ El deber general de cooperación. La doctrina identifica en la Convención un deber general de cooperación entre las partes. Dicha obligación se deduce de las obligaciones adicionales que la Convención establece junto a las obligaciones principales: ello se pone de manifiesto, por ejemplo, en el deber de conservación de las mercaderías que, posteriormente, habrán de ser devueltas (arts. 85 y 86); en el deber de aceptar un cumplimiento a posteriori (arts. 34, 37 y 48); en el deber de evitar daños (art. 77); en las diversas y numerosas obligaciones directas e indirectas de informar a la otra parte.

De los preceptos citados, así como de los arts. 32 y 60 de la Convención, cabe deducir el principio general según el cual cada parte tiene el deber de facilitar a la otra el cumplimiento del contrato y el de no poner en peligro el fin del mismo.

Además, en ciertos casos, supone la existencia de un deber general de información. Pero dado que el deber de informar a la otra parte es regulado de forma detallada, parece dudoso que, además, exista una obligación general de información más amplia. Por motivos de seguridad jurídica, las partes deberían poder deducir de forma inmediata de la Convención el momento y el tipo de información que están obligadas a dar ${ }^{53}$.

$\left.10 .^{\circ}\right)$ La obligación de evitación de daños. De acuerdo con la opinión mayoritaria, de la Convención cabe deducir la obligación general de las partes de evitación de daños a la otra parte dentro de lo razonable, lo que se recoge en el art. 77 de la Convención. El precepto impone a la parte que reclame una indemnización por daños y perjuicios la obligación de adoptar las medidas para reducir el daño propio en lo posible. Por otra parte, los arts. 85 y 86 de la Convención imponen en determinadas circunstancias a la parte que esté en posesión de mercaderías que deban ser devueltas a la contraparte un deber independiente de custodia y conservación. En los mencionados artículos subyace la idea generalizable de que la parte que ostente la custodia efectiva sobre las mercaderías está sujeta a un deber razonable de

53 El de que las partes, en una relación que se prolonga a lo largo del tiempo, tienen obligación de comunicarse para aclarar las ambigüedades); St. del US District Court, Southern District of New York, de 14 abril de 1992, caso Filanto Spa. vs.Chilewich International Corp., CLOUT, núm. 23. Se ha afirmado al respecto que «...The opinion may... be read as saying that the parties in a long-term relationship owe to each other a duty to communicate, a duty which ultimately may be derived from a duty to act in good faith». Cfr. WINSHIP, The UN Sales Convention and the Emerging Case Law, en NEUMAYER (coord.) EmptioVenditio Internationales. Basilea, 1997, pág. 228. 
custodia y de evitación de daños. Así, el deber de conservación del art. 85 de la Convención puede aplicarse no sólo a las mercaderías sino, también, por ejemplo, a los materiales puestos a disposición por el comprador.

11. $\left.{ }^{\circ}\right)$ La carga de la prueba. De acuerdo con la opinión doctrinal mayoritaria, de la Convención también se pueden derivar o desarrollar principios generales respecto a la carga de la prueba.

El art. 79 I de la Convención recoge explícitamente la distribución de la carga de la prueba, de forma que una parte sólo se liberará de su deber cuando pruebe que existe una razón para su exoneración. El análisis de determinados preceptos permite afirmar la existencia de un reparto de la carga de la prueba. Así, de expresiones como «salvo que» (unless, à moins que), cabe deducir que quien haga uso de la excepción deberá asumir la carga de la prueba. Algunos preceptos imponen, con carácter cuasi-imperativo, el reparto de la carga de la prueba, de forma que quien, de acuerdo con el art. 44 de la Convención, aduzca excusa razonable relativa a la omisión de la comunicación requerida, deberá aportar las pruebas pertinentes. De igual manera, en relación con el art. 26, en supuestos de comunicaciones incompletas o no recibidas, la carga de la prueba recaerá sobre quien haya hecho la comunicación.

Del conjunto de esta regulación cabe extraer tres principios generales respecto de la carga de la prueba: $1^{\circ}$ ) Como regla general cada parte tendrá que acreditar la existencia de los presupuestos fácticos de aquellas normas de las que pretenda extraer para sí consecuencias jurídicas favorables; $2 .^{\circ}$ ) Quien invoque una regla de excepción, deberá acreditar sus presupuestos fácticos; $3 .^{\circ}$ ) Aquellos hechos que correspondan al ámbito competencial propio de una de las partes y que tenga un mejor conocimiento de los mismos, deberán ser acreditados por aquella parte que ejerza el control sobre dicho ámbito ${ }^{54}$.

$\left.12 .^{\circ}\right)$ La obligación de indemnización por daños y perjuicios. En la Convención subyace el principio estructural general según el cual cada parte deberá indemnizar íntegramente a la otra el daño derivado de un incumplimiento contractual respecto del cual no se pueda exonerar (art. 79). En principio, esta regla puede ser deducida de los arts. 45 I (b) y 61 I (b), en conexión con el art. 74 y siguientes de la Convención, y es aplicable al incumplimiento de cualquier obligación derivada de un contrato. De las anteriores disposiciones se deduce un principio general

54 Principio de que la carga de la prueba de los defectos de las mercaderías y de su denuncia en plazo corresponde a quien los alega (arts. 38 y 39) (54); Cfr. St. del Handelsgericht de Zurich, de 9 de septiembre de 1993, en CLOUT, n. ${ }^{\circ} 97$. 
que también será de aplicación a obligaciones de las partes pactadas adicionalmente o ampliadas ${ }^{55}$.

\section{Principios relativos a los derechos de las partes}

$\left.13 .^{\circ}\right)$ La simultaneidad de las prestaciones. Si bien no cabe hablar de un principio claramente establecido al respecto, del art. 58 I de la Convención se puede extraer la regla de que, a menos que las partes hubieran establecido otra cosa, únicamente están obligadas a cumplir las prestaciones de forma simultánea, por lo que ninguna de las partes está obligada a un cumplimiento anticipado. Bien es cierto que el comprador, antes de que le sea exigible el pago, deberá haber tenido la oportunidad de examinar las mercaderías (inspección externa y superficial) (art. $58 \mathrm{III})$.

Asimismo, en caso de resolución del contrato, la restitución de las prestaciones también deberá ser simultánea (art. 81 II 2 de la Convención). Por tanto, el principio de la simultaneidad, característico de las relaciones contractuales sinalagmáticas, puede ser aplicado con carácter general a las prestaciones entre las partes. De dicha norma se deduce que, en aquellos supuestos de prestaciones pactadas adicionalmente (como por ejemplo, el montaje), el pago será debido tras el cumplimiento íntegro de la prestación, produciéndose su vencimiento a la finalización de la prestación.

14..$^{\circ}$ La compensación de reclamaciones. La Convención no regula la compensación, la cual queda sometida al ordenamiento jurídico interno designado por la norma de conflicto.

Sin embargo, podrían contraponerse reclamaciones opuestas dimanantes de un mismo contrato de compraventa sometido a la Convención. Un ejemplo de lo anterior podría hallarse en una indemnización por daños y perjuicios a consecuencia de defectos en las mercaderías que hubieran producido daños, pretensión que el comprador puede querer oponer frente a la reclamación del pago por el vendedor. En tal caso podría aceptarse la compensación directamente derivada de la Convención, lo que no resultaría novedoso pues la Convención contempla una compensación de este tipo, en su art. 84 II, para el caso de que el comprador hubiera obtenido alguna ventaja del uso de las mercaderías restituidas y pueda reclamar la devolución del precio de compra.

55 Principio el de que el perjudicado por un incumplimiento contractual deber ser reintegrado por la totalidad de los daños patrimoniales sufridos (art. 74 y 78) (55); Cfr. Laudo arbitral de la Cámara Federal de Comercio de Viena, de 15 junio de 1994, en CLOUT, núm. 93. 
El principio anteriormente citado relativo a la simultaneidad de las prestaciones también podría suponer un argumento a favor de la compensación de reclamaciones dinerarias derivadas de la propia Convención sin mayores requisitos y sin recurrir al sistema conflictual ${ }^{56}$.

15. $\left.{ }^{\circ}\right)$ El derecho de retención. Del principio de la simultaneidad del cumplimiento de las obligaciones contractuales se sigue que una parte podrá diferir su prestación hasta que la otra dé cumplimiento debido a su prestación. Por su parte, el art. 71 faculta, caso de duda razonable acerca del cumplimiento, a no cumplir con la obligación propia (apdo. 1), o a que el vendedor prosiga en poder de la mercancía cuando ésta estuviera siendo transportada al comprador (apdo. 2).

De lo anterior cabe deducir la regla general de que la Convención, salvo en los casos anteriormente descritos, no contempla el derecho de retención, no siendo necesario acudir al sistema conflictual para la aclaración de la cuestión, que sólo será de aplicación cuando una de las partes pretenda ejercer un derecho de retención derivado de pretensiones no sometidas a la Convención.

\section{Principios relativos a la transmisión del riesgo}

16. $\left.{ }^{\circ}\right)$ La transmisión del riesgo. Como se ha indicado anteriormente, los arts. 67 II y 69 III de la Convención hacen depender la transmisión del riesgo del hecho de que las mercaderías en cuestión constituyan el objeto inequívoco de determinado contrato de compraventa. Si bien el art. 68 de la Convención (relativo a la transmisión del riesgo durante el transporte de las mercaderías) no contiene esta regla, dicho precepto podría ser integrado mediante el criterio apuntado que podría ser generalizable y, asimismo, aplicable en situaciones análogas.

17. ${ }^{\circ}$ La transmisión del riesgo, transmisión de las cargas y transmisión del uso de las mercaderías. La Convención no contiene una regla general para el establecimiento de la fecha a partir de la cual el comprador pueda hacer uso de la mercancía y tenga que soportar las cargas de la misma. Sin embargo, la cuestión podría ser resuelta por recurso al principio de la transmisión del riesgo. En caso de duda, la fecha de la transmisión del riesgo será determinante para la transmisión del uso y de las cargas.

56 Ello podría ser de aplicación en caso de que no coincidieran las monedas de las reclamaciones dinerarias derivadas de la Convención. 


\section{Principios relativos al cómputo de los plazos contractuales}

18. $\left.{ }^{\circ}\right)$ El cómputo de los plazos. De acuerdo con el art. 20 II de la Convención, los días festivos y los no laborables no prorrogan el plazo de aceptación de una oferta, salvo que la entrega de la comunicación de aceptación no pudiere ser entregada por ser el día del vencimiento del plazo un día festivo o no laborable.

Este principio es susceptible de aplicación analógica. En este sentido puede ser empleado para el cómputo de otros plazos como, por ejemplo, el plazo para la realización de una prestación, de un pago, etc., los cuales igualmente se prorrogarán en función de los días festivos, siempre que la prestación, el pago, etc. no pudiese ser realizado por ser el último día del plazo un día festivo o no laborable. En consecuencia, puede quedar excluido el recurso al sistema conflictual para el cómputo de los plazos.

19. $\left.{ }^{\circ}\right)$ El principio del envío de las comunicaciones. El art. 27 de la Convención sanciona el criterio del envío de las comunicaciones en lo relativo a su Parte III, de forma que, por el hecho de su envío (en plazo), las declaraciones o comunicaciones son válidas. La recepción únicamente será necesaria cuando la Convención así lo establezca expresamente. Este principio también es de aplicación a la parte II de la Convención (formación del contrato). Sin embargo, para la validez de una oferta o de una aceptación, así como de otras declaraciones, la Convención exige expresamente su recepción (arts. 15 y 18 II). Pero, de conformidad con el principio general, para las declaraciones del art. 21 (comunicaciones respecto de aceptaciones tardías), únicamente es necesario su envío.

$\left.20 .^{\circ}\right)$ El principio de recepción de las comunicaciones. Para el caso de que fuere necesaria la recepción de la declaración de una de las partes, el art. 24 de la Convención define el concepto de recepción pero lo hace, expresa y únicamente, en lo relativo a la Parte II de la Convención.

Aun así, existe unanimidad acerca de la aplicabilidad general de la definición, es decir, también resultaría de aplicación a la Parte III de la Convención. Así, cuando los arts. 47 II, 48 IV, 63 II, 65 I y II y 79 IV requieran que una comunicación haya «llegado» a la otra parte, resultará de aplicación el art. 24.

21..$^{\circ}$ La improcedencia de requerimiento para el vencimiento. Según el art. 59 de la Convención, la reclamación del pago del precio será exigible una vez hubiere transcurrido el plazo de pago. La Convención no exige un requerimiento ni ninguna otra formalidad.

De lo anterior cabría deducir un principio general asimismo aplicable a otras reclamaciones de pago como, por ejemplo, devoluciones, indemnizaciones por daños y perjuicios, pagos por gastos e intereses. 
$\left.22 .^{\circ}\right)$ La comunicación a través de terceros. En ocasiones puede plantearse la cuestión de tener que precisar si una parte ha recibido una comunicación a través de un tercero. Igualmente, podría ser necesario averiguar si una comunicación ha sido recibida, si hubiera sido entregada a un empleado de la otra parte, o si es atribuible a una parte el conocimiento de vicios materiales o defectos legales que pudiera tener un empleado de dicha parte u otra persona dependiente de la misma, etc.

El art. 79 de la Convención (párrafos $1 .^{\circ}$ y 2..$^{\circ}$ ) puede ofrecer un principio general para la presunción de actuaciones y conocimientos, consistente en que una parte será responsable por las actuaciones y conocimientos de sus empleados y de aquellos terceros «de los que se sirva para la ejecución total o parcial del contrato».

\section{Principios relativos al pago del precio}

23. ${ }^{\circ}$ ) La moneda de pago. En general, de la Convención se deriva el principio según el cual, en caso de duda, el pago del precio deberá ser satisfecho en la moneda correspondiente al domicilio del vendedor. En defensa de este criterio cabe indicar que, además de la necesidad de hallar una solución jurídica unitaria, la Convención concede una cierta preferencia al acreedor. Así, por ejemplo, el pago deberá realizarse en el lugar donde tenga su establecimiento el acreedor (art. 57 I (c), debiendo cumplir el comprador las formalidades referentes al pago existentes en dicho lugar (art. 54) ${ }^{57}$.

$\left.24 .^{\circ}\right)$ El lugar de pago. En caso de duda, el art. 57 de la Convención establece que el lugar de pago del precio será aquél en que el vendedor tenga su establecimiento ${ }^{58}$, de lo que cabe extraer el principio general según el cual, en caso de duda, el lugar de cumplimiento de otras reclamaciones dinerarias (devoluciones, gastos, intereses, penalizaciones, etc.) será el del domicilio del acreedor. Sin embargo, el lugar de pago de indemnizaciones por daños y perjuicios sigue siendo discutido.

$\left.25 .^{\circ}\right)$ El devengo de intereses. De los arts. 78 y 84 I de la Convención cabe deducir el principio general ${ }^{59}$ según el cual una deu-

57 Principio de que todos los pagos derivados de la Convención (incluso los indemnizatorios) deben hacerse en el domicilio del acreedor (art. 57.1 (a) (57); vid. St. del OLG de Dusseldorf, de 2 julio de 1993, CLOUT, núm. 49.

58 Principio de que la divisa en que haya de hacerse el pago será la del lugar de pago (arts. 54 y 78 ).

59 Laudo arbitral de la Cámara Húngara de Comercio e Industria, de 5 de diciembre de 1995, CLOUT, n. ${ }^{\circ} 164$. 
da dineraria comienza a devengar intereses desde la fecha de su vencimiento $^{60}$.

\section{La utilización de los Principios UNIDROIT para la integración de las lagunas de la Convención de Viena de 1980}

Tras años de trabajos preparatorios, el Instituto para la Unificación del Derecho Privado (UNIDROIT) publicó, en 1994, los «Principios para los Contratos Comerciales Internacionales» (PCCI), fruto de una amplia comparación de ordenamientos jurídicos llevada a cabo por un grupo de trabajo compuesto por juristas de reconocido prestigio internacional procedentes de todos los Estados representados en el UNIDROIT ${ }^{61}$.

60 Por su parte, Magnus, art. cit. págs. 490 y sigs, hace referencia a los siguientes principios, cuya presencia en la Convención podría ser deseable, pero cuya aceptación y generalización no dispone de encaje en su texto. Se trata de:

- La cuantía de los intereses: se ha expresado la opinión de que la omisión por parte del art. 78 de la Convención respecto de la cuantía de los intereses a pagar puede ser suplida utilizando para ello los principios generales de la Convención. Sin embargo, como entiende la doctrina mayoritaria y la jurisprudencia, dicho planteamiento carece del adecuado respaldo. Por el contrario, no cabe extraer un parámetro para determinar la cuantía de los intereses de la propia Convención, por lo que sería necesario el recurso a un ordenamiento jurídico interno en relación con el supuesto concreto (por ejemplo, la ley del domicilio del acreedor), caso en el que se tendría que recurrir a la norma de conflicto.

- El orden de extinción: la jurisprudencia de los tribunales holandeses, en su interpretación de la LUVI, definieron como principio general el de que, caso de duda, los pagos deberán aplicarse en primer lugar a los intereses de demora, y posteriormente a la deuda pendiente más antigua. Sin embargo, la Convención tampoco contiene disposición alguna que permitiera sustentar la existencia de esta regla, aun cuando pudiera resultar operativa parece y pudiera corresponderse con una hipotética voluntad de las partes. En suma, no parece posible calificar el orden de extinción como principio general.

${ }^{61}$ En dicho grupo, dirigido por Bonell, estaban representados los ordenamientos jurídicos más relevantes del mundo. La primera versión de los Principios fue publicada por UNIDROIT en 1995, existiendo versiones posteriores reformadas (2005). Al respecto, vid. Bonell (ed. y coord), A New Approach to International Commercial Contracts, Kluwer Law International, The Hague-London-Boston, 1999; BonELL, The UNIDROIT Principles in Practice:The Experiende of the First Two Years, en «Uniform Law Review», 1997, págs. 33 y sigs; GIARDINA, Les Principes UNIDROIT sur les contrats internationaux, en «Journal de Droit International», 1995, págs. 547-558; quizá sea de especial interés, por las numerosas contribuciones recogidas, UNIDROIT Principles for International Commercial Contracts: A New Lex Mercatoria?, Institute of International Business Law and Practice, Publicación CCI, n. ${ }^{\circ}$ 490/1, 1995. En la doctrina en castellano, vid. MoRÁn Bovio (coord.) Comentario a los Principios de UNIDROIT para los Contratos del Comercio Interna- 
La definición o inducción de principios generales para la regulación de los contratos internacionales tiene a su favor la tradición en la doctrina internacionalista de derecho privado. Una antigua línea doctrinal ${ }^{62}$ ya había propuesto que, en aquellos casos en que el derecho invocado por la norma de conflicto no pudiese ser determinado, los principios jurídicos generales fuesen considerados como derecho supletorio, aun cuando ello impone unas exigencias máximas al juez. El estado del derecho comparado y el aumento del tráfico jurídico internacional permiten la traslación al juez, mediante la práctica de una labor comparativa de la obligación de la definición de principios jurídicos generales. Aún existen pocos principios jurídicos generales que, obtenidos por comparación entre ordenamientos jurídicos, sirvan, con carácter general, para dirimir disputas jurídicas de todo tipo y que, al mismo tiempo, confieran seguridad jurídica. Sin embargo, cabe calificar de adelanto el hecho de que, al menos en un campo concreto como es el de la compraventa internacional de mercaderías, exista un conjunto reconocido de principios jurídicos generales. La posibilidad de su generalización, así como la de los principios UNIDROIT, permiten alimentar la esperanza de que se desarrollen principios jurídicos generales, al menos para los contratos comerciales internacionales. En suma, y con carácter general, los PCCI pretenden superar la crítica expuesta anteriormente respecto de la unificación legislativa internacional, y son exponente del intento de creación de un instrumento más flexible y adaptable que aquello que pueda ser una convención o una ley modelo.

El método utilizado para la definición de los Principios resulta novedoso, pues no se trata de un Restatement de principios generales presentes en todos o en algunos de los ordenamientos jurídicos más relevantes, ni de un derecho normativo de grupos económicos, sino que, más bien, se trata de un intento de extracción de aquellos elementos co-

cional, Aranzadi, Madrid, 1999. De entre las diversas colaboraciones contenidas, es especialmente sugerente la de ILLESCAS ORTIZ, Los principios de UNIDROIT: ¿Una Nueva Lingua Franca para la Redacción de los Contratos Internacionales?, págs. 389-399. Es igualmente de interés, Perales Viscasillas, El Derecho Uniforme del Comercio Internacional: los Principios de Unidroit, en «Revista de Derecho Mercantil», 1997, págs. 221-297. Muy en especial Marrella, La Nuova Lex Mercatoria, en Galgano (dir.), «Tratatto di Diritto Comérciale e Diritto Publico dell'Economia», Tomo XXX, Padua, Cedam, 2003, págs. 464-472.

${ }^{62}$ La idea ya había sido propuesta por WENGLER, Les principes generaux du droit en tant que loi du contract, en «Rev. Critique de Droit International Privé», 1983, págs. 467-501. Recibió el posterior respaldo de ZwEIGERT, Diskussion in «Die Anwendung ausländischen Rechts im internationalen Privatrecht, Festveranstaltung und Kolloquium anläblich des 40jährigen Bestehens des Max Plank Instituts für ausländisches und internationals Privatrecht», vom 6., julio 1966, pág. 190; la postura fue retomada posteriormente por KöTZ, Allgemeine Rechtsgrundsätze als Ersatzrecht, en RabelsZ, 34, 1970, 663 ff. 
munes, que resultaren evidentes desde un punto de vista teórico y práctico, desde el sustrato de los ordenamientos jurídicos, de las convenciones de mayor relevancia así como de otras obras codificadoras internacionales como los Incoterms, para elevar el resultado de tal inducción comparativa al rango de principios. Como consideración complementaria a lo anterior, los PCCI han abierto un nuevo camino para la unificación internacional del derecho, pues no contienen un derecho unitario material directo ni una ley modelo que pueda ser aceptada o rechazada íntegramente, sino que establecen un catálogo de reglas que deben servir como modelo de regulación y ejemplo para destinatarios diferentes: en primer lugar, para el legislador nacional e internacional como modelo de su legislación; en segundo lugar, significan una referencia para quienes se encuentren en la tesitura de tener que proceder a una labor interpretativa de las normas y tener que colmar las lagunas de convenios internacionales o cuando no sea posible la determinación del derecho aplicable; finalmente, como ayuda para las partes de contratos mercantiles internacionales al redactar y ejecutar sus contratos. Sin embargo, es de señalar que las posibilidades mencionadas quedan supeditadas, en principio, a la condición de que los Principios únicamente tendrán carácter vinculante cuando las partes hayan pactado su aplicación.

En cuanto a la cercanía apreciable entre la Convención de Viena y los Principios UNIDROIT, pueden formularse las siguientes observaciones generales:

1. ${ }^{\text {a }}$ La apreciación de conexión y similitud entre los PCCI y los principios generales inspiradores de la CV es, probablemente, posible ya desde un primer momento. Como se ha indicado anteriormente, el art. 7 II de la Convención permite el recurso a los principios generales que subyacen a la Convención para colmar sus lagunas, aun cuando no hayan sido formulados de forma expresa. Por el contrario, en términos generales y tal como ha quedado anteriormente expuesto, los principios generales ajenos a la Convención no deberán ser tenidos en cuenta, lo que puede suscitar dudas en relación a la consideración de los Principios UNIDROIT. Sin embargo, sus redactores pretendieron, entre otras funciones, que los mismos sirvieran de ayuda a la hora de interpretar y colmar lagunas de convenios internacionales relativos a contratos comerciales. A pesar de todo, es de estimar que los Principios deberían ser tenidos en cuenta como principios generales complementarios de la Convención. La razón principal radica en que ponen de manifiesto una subs- 
tancial coincidencia con las disposiciones específicas de la Convención y con los principios generales de la Convención anteriormente mencionados, coincidencia ésta que no puede sorprender pues la Convención fue, en buena medida, el origen de los Principios UNIDROIT ${ }^{63}$.

2. ${ }^{a}$ Por otro lado, el procedimiento empleado para la creación de los Principios parece adecuado al estado actual de unificación jurídica. La CV supone la existencia de una regulación fruto de una comparación entre ordenamientos jurídicos. Por ello, con carácter general, se puede partir de la CV para la creación de un derecho general de los contratos, pues, al objeto de proporcionar respuestas a nuevas cuestiones y de procurar la mejora de soluciones ya existentes, bastaría con la generalización de sus disposiciones y su coordinación con las necesidades de los distintos sectores comerciales lo que, precisamente, constituyó la pauta de actuación del grupo de trabajo del UNIDROIT. Por ello, los resultados alcanzados podrían, en tanto en cuanto formulen principios generales no directamente deducibles de la Convención, ser utilizados para colmar las lagunas de la misma.

3. ${ }^{a}$ Por último, un análisis de los principios generales de la $\mathrm{CV}$, que reciben una general aceptación, permite afirmar que su contenido ha dejado de ser reducido, no limitándose a princi-

63 La línea de los pronunciamientos arbitrales en orden a la consideración de los Principios UNIDROIT como inspiradores de la Convención de Viena parece suficientemente establecida. En tal sentido, cabe mencionar:

—Laudos arbitrales del «Internationales Schiedsgericht der Bundeskammer der Gewerblichen», Viena, nos. SCH-4366 y SCH-4318, ambos de 15 de junio de 1994, que interpretan que, para la determinación del tipo de interés, se aplica el principio general que cabe extraer del art. 74 de la Convención de Viena, con lo que se consigue igual resultado que el derivado de la aplicación del art. 7 de los Principios UNIDROIT.

— St. del Rb Zwolle (Países Bajos), de 5 de marzo de 1997, que alude a los Principios UNIDROIT como criterio interpretativo para el derecho francés.

- Laudo arbitral CCI, 8128/1995, que cita los Principios UNIDROIT en relación con la determinación del tipo de interés, en los que habrá de fundamentarse el intérprete para la solución las lagunas de la Convención de Viena.

— Laudo arbitral CCI, 8769/1996, sin mayores razonamientos, aplicó el art. 7 de los Principios UNIDROIT, al entender se trataba del tipo de interés razonable en las transacciones mercantiles.

— Laudo arbitral CCI, 8817/1997, sobre un contrato de distribución en exclusiva en España y Portugal, en el que el árbitro decretó la aplicabilidad de la Convención de Viena, así como sus principios generales tal y como estaban recogidos en los Principios UNIDROIT. 
pios absolutamente genéricos de cuya aplicación no cabe esperar la formulación de soluciones cuando se trata de la resolución de casos concretos. En efecto, los principios inducidos no vienen referidos con carácter específico a cuestiones del contrato de compraventa sino que, en general, se trata de principios que podrían resultar de utilización también en relación a otras convenciones cuyo objetivo sea la unificación internacional del derecho contractual. Los principios anteriormente citados se derivan de la estructura y conceptos jurídicos de la Convención, aun cuando son susceptibles de generalización y contienen los elementos necesarios para el reforzamiento del armazón básico de los contratos. Por tanto, no es coincidencia que una gran parte de los mismos sean también incardinables en los principios de la lex mercatoria internacional y en los principios UNIDROIT.

\section{La posibilidad de la interpretación e integración de la Convención de Viena mediante la utilización de los Principios UNIDROIT}

Una posible aplicación de los Principios UNIDROIT se produce en los casos en los que se presenten dudas interpretativas o fuere necesario colmar eventuales lagunas apreciables en el contenido de convenciones internacionales de derecho uniforme. En tal sentido, el pár. 5 del Preámbulo señala que «Estos Principios pueden ser utilizados para interpretar o complementar textos internacionales de derecho uniforme».

Además, el comentario oficial a los Principios ${ }^{64}$ hace explícita mención de su aplicabilidad en cuanto medio para la interpretación e integración de convenciones internacionales. Dicho documento hace referencia a los Principios como instrumento de interpretación e integración de los convenciones internacionales ya existentes. En todo texto legislativo, de origen nacional o internacional, se presentan cuestiones relacionadas con el significado exacto de cada una de sus disposiciones. Además, las leyes, por su naturaleza, no pueden prever anticipadamente todos los casos en los que serán aplicadas. Cuando se aplican leyes internas, es posible recurrir a principios ya consolidados y a criterios hermenéuticos existentes dentro de cada sistema jurídico. La situación se presenta más incierta en relación con aquellos instrumentos que, a pesar de estar introducidos en los diferentes sistemas nacionales, hayan

${ }^{64}$ Cfr. UNIDROIT, Principios sobre los Contratos Comerciales Internacionales, Roma, 1995, págs. 5 y sigs. 
sido elaborados por vía convencional a nivel internacional. Según las teorías tradicionales, en estos casos también se debería recurrir a los principios y criterios interpretativos previstos en el derecho interno, tanto si se trata de la lex fori como del derecho que, según las normas de derecho internacional privado, sería aplicable en ausencia de derecho uniforme. Hoy en día, tanto los jueces ordinarios como los árbitros, tienden cada vez más a abandonar este tipo de planteamiento conflictual, tratando en cambio de interpretar e integrar las fuentes internacionales en relación con los principios autónomos y uniformes a nivel internacional. Esta orientación, expresamente ratificada en los convenciones más recientes, se fundamenta en el supuesto de que el derecho uniforme, incluso tras su incorporación a los diferentes sistemas jurídicos nacionales, se convierte sólo formalmente en parte integrante de estos últimos, mientras que, desde el punto de vista sustancial, no pierde su carácter original de cuerpo normativo que se ha desarrollado de forma autónoma a nivel internacional, destinado a una aplicación uniforme en el mundo. Hasta ahora, ha venido siendo tarea de los mismos jueces y árbitros buscar en cada uno de los casos estos principios y criterios autónomos de interpretación e integración de los instrumentos normativos internacionales, basándose en investigaciones comparativas sobre las soluciones adoptadas en los diferentes sistema jurídicos nacionales. Los Principios, podrían facilitar de forma importante su tarea en este aspecto.

Esta utilización de los Principios debe ser ponderadamente considerada pues se corre el peligro, ante la existencia de una laguna, de recurrir a los Principios UNIDROIT en lugar de hacerlo, primeramente, a los propios principios generales que puedan ser deducidos del texto internacional objeto de interpretación. Con todo, ésta es una de las funciones que los Principios de UNIDROIT están llamados a desarrollar ${ }^{65}$ por la propia naturaleza incompleta o fragmentaria de los textos internacionales que conforman el Derecho Uniforme del Comercio Internacional ${ }^{66}$.

Si los Principios han sido también concebidos con una función interpretativo-integrativa de convenciones internacionales de derecho

$65 \mathrm{Al}$ respecto, se ha afirmado «...the UNIDROIT Principles deal with a number of matters which are either excluded or not sufficiently covered in CISG». Cfr. BoneLL, An International Restatament of Contract Law, Nueva York, Transnational Juris Publications, 1994, pág. 44.

66 «The potential use of the UNIDROIT Principles as a means of interpreting and supplementig the CISG must be examined first in light of CISG article 7 (2)». Cfr. GARRO, cfr. The Gap-Filling Role og the UNIDROIT Principles in International Sales Law, en «Tulane Law Review», abril 1995, págs. 1155-1156. 
uniforme, habría que recordar que, en la jurisprudencia, aún no se ha apaciguado el debate ${ }^{67}$ sobre la vexata questio de si la interpretación tiene que hacerse de acuerdo con criterios autónomos, o bien mediante parámetros extraídos de la ley aplicable en virtud de los tradicionales criterios de localización. En términos generales, la doctrina se pronuncia a favor de la influencia de los Principios sobre la CV, ante la consideración de que los Principios pueden llegar a convertirse en un conjunto de principios comunes ${ }^{68}$ necesarios para alcanzar la uniformidad y harmonización del derecho mercantil internacional, a pesar de su carácter no obligatorio, o en la pieza central de convenciones internacionales $^{69}$.

Un ejemplo de lo anterior ${ }^{70}$ lo ofrece el régimen de la responsabilidad precontractual en la CV. Puede indicarse que la responsabilidad precontractual es una laguna de la Convención sin que sea posible encontrar en el texto de la Convención algún principio general. Por ello, en principio, la regulación de la responsabilidad precontractual debería dejarse al derecho nacional que resulte aplicable por mandato del art. 7.2 CV. Esta dejación de la responsabilidad contractual a los diversos derechos nacionales puede ser superada por la aplicación de los Principios UNIDROIT, particularmente por la aplicación del art. 2.15 PCCI (Negociaciones con mala fe) y del 2.16 PCCI (Deber de confidencialidad). Esta solución evitaría los inconvenientes del recurso a los diversos ordenamientos internos y permitiría la consecución de una aplicación uniforme para las transacciones internacionales, máxime cuando los diferentes derechos internos no son unánimes acerca de la naturaleza jurídica que reviste la responsabilidad en esta fase de la vida del contrato, ni acerca del contenido del principio de buena fe, ni acerca de las soluciones para la parte afectada, así como el cálculo de los daños que bascula entre el interés positivo y el negativo, si bien este último criterio es el generalmente aceptado. En tal sentido, Van

67 Cfr. Kahn, Les Conventions Internationales de Droit Uniforme Devant les Tribunaux Arbitraux, en «Uniform Law Review», 2000, págs. 121 y sigs.

68 La expresión «a backbone of common principles» es de FERRARI, en Le champ d'application des «Principes pour les Contrats Commerciaux Internationaux» elaborés par UNIDROIT, en «Rev. Internationale de Droit Comparé», 1995, pág. 1234.

69 Por su parte, GARRo completa la anterior expresión señalando que tales principios comunes son «necessary to achieve uniformity and harmonization of international commercial law, despite their nonbinding character, or in the centerpiece of international conventions»; cfr. The Gap-Filling Role og the UNIDROIT Principles in International Sales Law, cit. pág. 1155.

70 Perales Viscasillas, El Derecho Uniforme del Comercio Internacional, cit. págs. 255-257. 
Houtte $^{71}$ pone de relieve que una de las grandes innovaciones de los Principios UNIDROIT radica en la definición de estándares para el desarrollo de las negociaciones.

Otro ejemplo lo puede ofrecer el supuesto de la contratación construida sobre cláusulas estándar, supuesto en el que se pueden plantear problemas acerca de la validez de las llamadas «cláusulas sorpresivas». Al respecto, de acuerdo con el art. 2. 20 (1) PCCI, «toda estipulación incorporada en cláusulas estándar cuyo contenido o redacción, material o formal, no fuese razonablemente previsible por la otra parte». Este precepto, recogido en los PCCI, no tiene paralelo en la CV por lo que la aplicación de los Principios sería deseable, lo que no impediría que se llegase al mismo resultado sobre la base de aplicar el principio de la razonabilidad ${ }^{72}$.

Por otra parte, tal como indica el Preámbulo, esta solución contribuirá a lograr una mayor equidad durante la resolución de la disputa, ya que no se aplicará el derecho nacional de una de las partes, lo que en el caso de contratantes pertenecientes a ordenamientos jurídicos diferentes podría suponer una ventaja para aquel cuyo derecho se aplica.

\section{Los supuestos de dificultad en la coordinación entre la Convención de Viena y los Principios UNIDROIT}

Pese a lo anteriormente expuesto, no se deben desconocer determinados problemas que pueden plantearse para un adecuado engranaje y debida coordinación entre la CV y los PCCI lo que parece posible, ya desde un principio, pues se trata de textos con diferente alcance, siendo el segundo de aplicación a cualquier tipo o clase de contrato.

\section{A) LAS DIFERENCIAS APRECIABLES ENTRE LAS REGULACIONES DE AMBOS TEXTOS}

El hecho de que la regulación de los Principios UNIDROIT se aparte en determinadas cuestiones de la regulación de la CV puede llevar a

$71 \mathrm{El}$ art. 2. 15 PCCI sanciona la responsabilidad de las partes caso de ruptura de las negociaciones de mala fe. Sobre la cuestión, VAN HouTTE, «one of the great innovations of the UNIDROIT Principles is that they provide standards for conducting negotiations», cfr. The Unidroit Principles of International Commercial Contracts, en «Arbitration International», 1995, vol. 11, pág. 377.

72 Los árbitros, sin duda, tenderán más fácilmente a complementar los textos internacionales vigentes con los Principios de UNIDROIT, como lo demuestran los laudos del International Schiedsgericht comentados acerca de la determinación del tipo de interés. No obstante, sería deseable que los jueces nacionales se sumen también a este movimiento, para lograr efectivamente la consecución de un Derecho Uniforme en el comercio internacional. 
una interpretación errónea de la Convención; particularmente puede influir en la solución que el juez o arbitro dé ante un determinado conflicto. Ejemplos de lo anterior, tal como señala Perales Viscasillas, pueden ser los siguientes:

El art. $78 \mathrm{CV}$ establece el derecho que asiste a las partes a la percepción de intereses, derecho que también acogido por el art. 7.4. 9 PCCI, viniendo a reflejar un uso ampliamente reconocido en el comercio internacional. A diferencia de los Principios de UNIDROIT, la Convención no ha especificado el tipo de interés de aplicación. Pues bien, es claro que el tipo de interés se configura en la Convención como una laguna, por lo que, en principio, deberá buscarse una solución al problema en la propia Convención. La solución ha de tener en cuenta los objetivos de la Convención plasmados en el art. $7 \mathrm{CV}$, principalmente la finalidad de conseguir el máximo de uniformidad aplicativa de la Convención evitando, en la medida de lo posible, el recurso a la norma de conflicto y, consecuentemente, a los ordenamientos internos.

Otro ejemplo lo proporciona la parte II de la CV relativa al proceso de formación del contrato. El art. $19 \mathrm{CV}$ regula la formulación de una contraoferta y establece, al respecto, que la respuesta a la oferta no puede ser considerada como aceptación, sino como contraoferta, cuando en ella se han incluido adiciones, limitaciones o modificaciones en relación con la oferta inicial (art. 19. $1 \mathrm{CV}$ ). Se acoge el conocido principio de la mirror image rule o «regla del espejo».

Los Principios UNIDROIT, por su parte, regulan la formulación de una contraoferta en su art. 2.11 (aceptación de la oferta que incluye modificaciones a la misma) en términos muy similares a los párrafos $1 .^{\circ}$ y $2 .^{\circ}$ del art. $19 \mathrm{CV}$. Por contra, el párrafo 3 del art. $19 \mathrm{CV}$ no ha sido acogido por los PCCI. La «batalla de formularios» se regula en el art. 2. 22 PCCI, precepto dedicado por los Principios UNIDROIT a la fase de formación del contrato dispensando acogida a la ya mencionada knock out rule. El hecho de que la Convención no contenga una regla específica para la «batalla de formularios», lo que es regulado por los Principios UNIDROIT, puede inducir a pensar que la CV no regula esa cuestión, por lo que el juez o árbitro podrían sentirse tentados de aplicar la solución acogida por los redactores de UNIDROIT con la finalidad de interpretar la CV. Tal situación, por otra parte, puede llegar a producirse si el juez o el arbitro permanecen ajenos a los objetivos de la Convención, a la historia legislativa del art. 19 CV (que claramente demuestra que la «batalla de formularios» no es una laguna en la Convención) y se dejan influenciar por la resistencia que una parte de la doctrina sobre la $\mathrm{CV}$, especialmente la de origen angloamericana, tiene frente a la aplicación de la last shot rule. 
B) LA DETERMINACIÓN DE LA PREEMINENCIA ENTRE AMBOS TEXTOS

Un problema adicional que se puede presentar al árbitro o al juez es el de determinar la regulación que prima sobre la otra cuando la Convención y los Principios se aplican a determinado contrato de compraventa, siempre teniendo en cuenta que se trate de situaciones en las que ambos textos acojan soluciones dispares. Habrán de distinguirse distintas situaciones:

1. ${ }^{a}$ Aplicabilidad de la Convención ante el silencio de los contratantes al respecto y elección expresa por las partes de los Principios UNIDROIT. En este caso, resulta que ambos textos son aplicables a la transacción, puesto que la Convención es inmediatamente aplicable al formar parte del derecho interno y los PCCI lo son por la elección expresa de las partes. La regulación preeminente será la de los Principios, ya que el art. $6 \mathrm{CV}$ permite a las partes la exclusión de la regulación de la Convención, siendo determinante a estos efectos la elección expresa de los Principios UNIDROIT. La Convención quedará totalmente excluida de la transacción en aquellos aspectos en que la regulación que acoja sea diferente a la de los Principios.

2. ${ }^{a}$ Aplicabilidad de la Convención por acuerdo de las partes, independientemente de que la misma resultase aplicable al formar parte del derecho interno de los Estados donde radican los establecimientos de los contratantes, y acuerdo expreso de aplicación de los Principios UNIDROIT. En esta circunstancia, las reglas de la Convención se aplicarán antes que las de los Principios en virtud del principio lex specialis derogat generali. Este principio podría también aplicarse en relación con la primera de las hipótesis, ya que el juez o el árbitro (especialmente el primero) podría considerar más adecuada la normativa contenida en la CV por ser la ley especial y, además, por ser derecho interno.

Las dos situaciones descritas demuestran que la función de los Principios UNIDROIT en el sentido de complementar o ayudar en la interpretación de otros textos internacionales debe ser tomada con cautela, sin que ello sea un obstáculo para que efectivamente pueda producirse una influencia recíproca entre ambos, esto es, que los Principios UNIDROIT puedan servir como instrumento para la integración del derecho uniforme existente, y viceversa. Un ejemplo de esto último lo proporciona el ya mencionado art. $19 \mathrm{CV}$. Ha quedado indicado que el art. 2.11 PCCI (aceptación de la oferta incluyendo modificaciones a la 
misma) no ha acogido un párrafo similar al art. 19. $3 \mathrm{CV}$. No obstante, el comentario al art. 2. 11 PCCI se acerca mucho al listado recogido en el art. 19. 3 CV (82). Pues bien, se observará que en este punto puede llegar a sostenerse una influencia de la Convención sobre los Principios en sentido inverso al considerado por el Preámbulo, de forma que la Convención puede servir para complementar (o interpretar) los Principios UNIDROIT.

\section{La utilización de los Principios UNIDROIT por los Tribunales internos}

La jurisprudencia interna de diversos países ha hecho mención y ha utilizado los Principios UNIDROIT para la interpretación e integración de la Convención de Viena, lo que puede revestir particular relevancia en aquellos casos en que tal utilización se produjo a instancia del tribunal, sin que los contratos respectivos hicieran remisión a los $\operatorname{mismos}^{73}$ ).

La St. de la Cour d'Appel de Grenoble, de 24 de enero de $1996^{74}$, se pronunció a propósito de un litigio entre una sociedad norteamericana y otra francesa relativo al transporte de una maquinaria hasta Francia a ser hecho por la primera de las citadas. La maquinaria sufrió daños durante el transporte como consecuencia de su inadecuado embalaje. Sin embargo, una cláusula del contrato, prácticamente, eliminaba toda responsabilidad del transportista, pues limitaba su responsabilidad económica a cifras puramente simbólicas. El juez francés hizo expresa mención a los Principios UNIDROIT, en los que se fundamentó, y concluyó que, en caso de ambigüedad, las cláusulas de un contrato se interpretan preferentemente contra quien las hubiera propuesto, por lo que respaldó la postura de la demandante francesa.

La St. asimismo de la Cour d'Appel de Grenoble, de 23 de octubre de $1996^{75}$, se pronunció sobre un contrato entre una sociedad francesa y

73 Cfr. Bonell, A New Approach to International Commercial Contracts, Actas del «XVth International Congress of Comparative Law», Kluwer Law International, 1999, págs. 13 y sigs. El autor se refiere a pronunciamientos judiciales de tribunales de diversos países en tal sentido, mencionados y analizados en las posteriores y diferentes ponencias nacionales. Sobre la cuestión, es de señalar la base de datos de UNILEX. info, actualizada hasta los inicios del presente año 2005, y que contiene más de un centenar de pronunciamientos judiciales y, sobre todo, arbitrales, sobre el uso recibido por los Principios UNIDROIT como complementarios de la Convención de Viena.

${ }^{74}$ St. del caso Societé Harper Robinson c. Societé Internationale de Maintenance et de Rëalisations Industrielles (SIMRI) et autres, en «Uniform Law Review», 1997, pág. 184.

75 Caso Scea GAEC Des Beauches Bernard Bruno c. Societé Teso Ten Elsen GMBH \& $C O K G$, en «Uniform Law Review», 1997, vol. 1, pág. 185. 
otra alemana, estando esta última obligada al suministro de determinados bienes por los que cobró un sobreprecio no pactado. El tribunal estableció que el art. 57 de la CV determina que el pago del precio debe hacerse en el domicilio del acreedor, y ello a título de principio general. Al respecto, el tribunal dictaminó que ello era, además, expresión de un principio enunciado en el art. 6. 1. 6 de los Principios UNIDROIT, válido y aplicable, no sólo en cuestiones de compraventa internacional, sino en cualquier otro contrato del comercio internacional. Con tal pronunciamiento, el tribunal llevó a cabo una labor de acercamiento y armonización entre ambos textos.

La St. de la Cour d'Appel de París, de 5 de marzo de $1998^{76}$, enjuició un caso en el que el tribunal se debía pronunciar sobre la impugnación presentada contra un laudo arbitral que se había fundamentado en los Principios UNIDROIT en cuanto usos del comercio internacional, y ello aun cuando las partes habían sometido su contrato a la ley francesa. Sin embargo, el árbitro apreció una laguna en el derecho francés que no le permitía establecer los efectos de la resolución del contrato, lo que le llevó a recurrir a los PCCI para colmar tal laguna legal interna. El razonamiento del árbitro resultó respaldado por el tribunal.

Una sentencia de un juez holandés ${ }^{77}$ hizo mención a los Principios UNIDROIT con el fin de resolver una cuestión surgida en relación con la interpretación de la CV. El caso se refería a un contrato de venta de pescado estipulado entre un agente de comercio francés y un comprador holandés. Tras la primera entrega, el comprador rechazó las siguientes entregas, como consecuencia de las reclamaciones de sus clientes acerca de la calidad del pescado. Según la parte actora francesa, el derecho del comprador a reclamar un defecto de conformidad de la mercancía había caducado, puesto que este último no había denunciado el defecto dentro del plazo correspondiente. El demandado, por su parte, alegó que el defecto no podía razonablemente ser descubierto en el breve plazo previsto en el contrato. El juez holandés, tras establecer que el contrato quedaba bajo el campo de aplicación de la CV, se refirió a su art. 39, pár. 1, según el cual el comprador habrá de comunicarse con el vendedor dentro de un plazo razonable a partir del momento en que haya descubierto la falta de conformidad o debiera haberla descubierto. Según el Tribunal holandés, con el fin de interpretar dicho art. de la CV, había que tomar como referencia la ley aplicable y el

\footnotetext{
76 St. del caso Societé Forasol c. Societé mixte Franco-Kazakh CISTM, en «Rev. Arbitrage», 1999, págs. 86-90.

77 St. del Rd. Zwolle (Países Bajos), de 5 de marzo de 1997, CME Coopérative Maritime Etaploise SACV vs. Bos Fishproducts Urk, en UNILEX. Info.
} 
modo en que el principio de buena fe se encontraba disciplinado en el ordenamiento referido de acuerdo con el art. 7, 2. de la CV. En este caso concreto, se trataba de la ley francesa, y el Tribunal, tras examinar la opinión de la doctrina y jurisprudencia francesas, concluyó que, en ese ordenamiento, prevalecía el concepto de la buena fe subjetiva. Por ello, aún evocando el concepto más amplio de buena fe tomado en consideración en los Principios UNIDROIT (relevante con arreglo al art. 5, pár. 1, de la CV, pero no decisivo según el juez competente) aceptó la tesis de la parte contraria que sostenía la caducidad del derecho de denuncia de defectos en la mercancía vendida, y condenó al comprador holandés.

La St. del US. District Court de California, de 7 de diciembre de $1998^{78}$, se pronunció sobre un contrato entre el Ministerio de Defensa iraní y la sociedad norteamericana Cubic Defense Systems Inc. Tras la revolución iraní, las autoridades suspendieron todos los pagos a la empresa norteamericana, por lo que ésta instó el procedimiento arbitral contractualmente previsto ante la CCI que emitió laudo n. ${ }^{\circ} 7365$, de 5 de mayo de 1997. El árbitro dictó resolución fundamentándose en el art. 6. 2. 3. PCCI, en los arts. 5.1. y 5. 2, así como en el art. 7. 3. 6. de los Principios UNIDROIT, y respaldó en cierta medida la posición del Gobierno iraní. Este último solicitó la concesión del exequátur ante un tribunal de California para obtener la restitución de algunas cantidades de dinero indebidamente pagadas. El tribunal se pronunció en el sentido de que los árbitros habían procedido correctamente, afirmando que los Principios UNIDROIT, la lex mercatoria y las normas transnacionales constituyen normas de derecho.

Por su parte, St. del Federal Court de Australia, de 30 de junio de $1997^{79}$, aplicó los PCCI para la interpretación del propio derecho australiano, mientras que otras dos sentencias ${ }^{80}$ de la New South Wales Supreme Court, se fundamentaron igualmente en los Principios UNIDROIT para acoger el principio de buene fe como integrante del derecho australiano, noción que no resulta de fácil admisión y comprensión para los sistemas del Common Law.

78 St. del caso The Ministry of Defence and Support for the Armed Forces of the Islamic Republic of Iran vs. Cubic Defense Systems Inc, 29 F. Supp. 2d 1168, en Yearbook, 1999, págs. 875-881.

79 St. del caso Hughes Aircraft Systems International vs. Airservices Australia, en «Diritto del Commerzio Internazionale», 2001, págs. 210 y sigs., con comentario de BoNELL sobre la misma.

${ }^{80}$ La primera de ellas, sobre el caso Alcatel Australia Ltd. vs. Scarcella \& Ors Matter; la segunda, de 1 de octubre de 1999, caso Aiton vs. Transfield, en «Uniform Law Review», 2000 , pág. 838. 
4. La Convención de Viena y los Principios UNIDROIT en el arbitraje de derecho

La praxis relacionada con las diferencias comerciales internacionales dirimidas por los árbitros internacionales pone de manifiesto que han utilizado los Principios UNIDROIT como medio de interpretación e integración de convenciones internacionales de derecho material uniforme. En la praxis hasta ahora conocida, las partes no habían formulado solicitud específica al árbitro de interpretar una convención de derecho uniforme en sentido transnacional, sino que han sido los árbitros quienes han recurrido a este método identificando en los Principios UNIDROIT las referencias normativas necesarias para colmar las lagunas existentes en las convenciones internacionales. En este tipo de cuestiones, los árbitros han utilizado los Principios fundamentalmente para la interpretación e integración de la Convención de Viena de 1980. Ello se ha fundamentado, adicionalmente, en la consideración del nexo entre la CV y los Principios UNIDROIT puesto de manifiesto en el art. 7 de la $\mathrm{CV}$, que enfatiza que en la interpretación de la presente Convención se tendrán en cuenta su carácter internacional y la necesidad de promover la uniformidad en su aplicación.

Así, el art. 7.4.9 de los Principios UNIDROIT ha permitido determinar la autonomía del derecho a la percepción de intereses y el tipo de interés para el cálculo del monto de los intereses por impago de una suma de dinero, resolviendo así una duda acerca de la interpretación del art. 78 de la CV. En esta categoría se sitúa el laudo CCI n. ${ }^{\circ} 8128$ de 1995. Otras aplicaciones de los Principios se han puesto de manifiesto en los laudos CCI n. ${ }^{\circ} 8769$ de 1996 y n. $^{\circ} 8817$ de 1997.

En el laudo CCI n. ${ }^{\circ} 8128$ de 1995, el árbitro recurrió a los Principios UNIDROIT para interpretar e integrar la CV. El litigio tuvo su origen en un contrato de venta de fertilizante químico en sacos, estipulado entre una sociedad austriaca y una sociedad suiza ${ }^{81}$. El comprador inició el procedimiento arbitral ante el retraso de los plazos de la entrega. El vendedor alegaba que los defectos encontrados por el comprador dependían de hecho imputable a un tercero, suministrador del mismo vendedor. El árbitro, una vez constatada la ausencia de elección de derecho aplicable, basándose en el art. 70, pár. 2 de la $\mathrm{CV}$, condenó al vendedor al resarcimiento de daños y perjuicios, puesto que, en ese caso, no se constataba la presencia de una causa de exoneración de la responsabilidad del vendedor. Además, el árbitro observó que la CV no permitía

81 En «Journal de Droit International», 1998, págs. 1025-1028, con comentario de HASCHER. 
determinar un tipo de interés resarcitorio y, por lo tanto, decidió aplicar un tipo de interés internacional, llegando al tipo LIBOR en vigor en la plaza de Londres. Esta decisión, se sustentaba en el art. 7.4.9, párrafo 2. ${ }^{\circ}$ de los Principios UNIDROIT, además de en el art. 4. 507, párrafo 1. ${ }^{\circ}$, de los PCCI, esto es, en aquellos principios generales a los que la misma CV hace referencia en el art. 7, párrafo $2 .^{\circ}$. Por lo tanto, el árbitro determinaba un tipo de interés equivalente al LIBOR incrementado en un dos por ciento. De esta forma, el árbitro coincidió con la jurisprudencia que sostiene, en caso de lagunas en la $\mathrm{CV}$, que hay que recurrir a los principios generales y no localiza la relación en el ordenamiento del Estado competente por remisión de las normas de conflicto ${ }^{82}$.

Un ejemplo adicional del empleo de los Principios UNIDROIT con fines integrativo-interpretativos de la CV, se encuentra en el laudo de la CCI n. ${ }^{\circ} 8769$ de 1996. De forma similar a lo ya observado en el laudo de CCI n. ${ }^{\circ} 8128$, el árbitro colmó una laguna de la CV mediante la aplicación de los Principios UNIDROIT en materia de determinación de los intereses por impago de una suma de dinero.

Se trataba de un contrato estipulado entre una sociedad francesa y una sociedad austriaca cuyo objeto era la producción y suministro de maquinarias. La sociedad francesa, actora, emprendió el procedimiento arbitral reclamando el comportamiento doloso de la parte contraria por carencias en las especificaciones técnicas pactadas en contrato, además de la falta de registro de una patente y, por lo tanto, sostenía, inter alia, la resolución injustificada del contrato y el impago de lo debido, y pedía, por vía reconvencional, el resarcimiento de los daños y perjuicios sufridos. El árbitro único, una vez fijado la sede en Zurich, apuntó la elección expresa del derecho francés en el contrato, declaró aplicable la $\mathrm{CV}$ y, rechazando las tesis de la parte actora, condenó a la misma al resarcimiento de los daños y perjuicios. La exacta cuantificación de los daños no podía realizarse en base a la CV (ex art. 78) y, por lo tanto, evitando proceder a la localización, resolvió la cuestión del quantum refiriéndose al art. 7.4.9., párrafo $2 .^{\circ}$, de los Principios UNIDROIT argumentando que «the sole arbitrator considers it appropriate to apply a commercially reasonable interest rate (see Art. 7.4.9. UNIDROIT Principles). The interest rate claimed is commercially reasonable for the award currency, austrian schillings».

En el laudo posterior, n. ${ }^{\circ} 8817$ de 1997, en cambio, el laudo de CCI no se plantearon cuestiones de integración de la $\mathrm{CV}$, puesto que los

82 Aún más, el árbitro apuntó una convergencia entre los Principios de UNIDROIT y los Principios de derecho europeo de los contratos, suscitando interrogantes acerca de la relación entre los principios generales y la lex mercatoria. 
Principios UNIDROIT fueron considerados por el árbitro como un todo único y armónico con la Convención.

También en este caso específico, la controversia se originó en la rescisión injustificada por una de las partes como consecuencia del recurso de algunas circunstancias consideradas unilateralmente como causa legítima de resolución. El árbitro único, tras sentar la aplicación de la CV, consideró los Principios UNIDROIT como un complemento natural de la convención misma, y afirmó que las disposiciones de la Convención y de sus principios generales, reunidos actualmente en los Principios UNIDROIT relativos a los contratos del comercio internacional, resultan perfectamente adaptados a la resolución del litigio ${ }^{83}$. Los fundamentos normativos del razonamiento del árbitro, se centraron en el art. 1.8 de los Principios en materia de usos y prácticas implementadas entre las partes, además de en el art. 7.4.8 en relación con la obligación de la mitigación de los daños. En base a estas referencias, el árbitro condenaba a la demandante al resarcimiento de daños y perjuicios derivados de la resolución del contrato.

\section{La Convención de Viena y los Principios UNIDROIT en el arbitraje de equidad}

Junto a la aplicación de los Principios UNIDROIT en el marco del arbitraje de derecho, se han producido aplicaciones de los Principios en el ámbito del arbitraje de equidad. De forma similar a lo observado en relación con el arbitraje de la CCI, los Principios UNIDROIT han sido utilizados por los árbitros con el fin de interpretar e integrar una convención internacional de derecho uniforme. Esto se ha producido en diversos casos, en los que los Principios han tenido aplicación en materia de determinación del tipo de interés aplicable con el fin de determinar el quantum del resarcimiento del daño.

1) Dos laudos emitidos por el Tribunal Arbitral Internacional de la Cámara Federal de Comercio de Viena se refieren a otras tantas controversias relacionadas con contratos para el suministro de chapa, estipulados entre un vendedor austriaco y un comprador alemán. Las mercancías debían ser entregadas «Fob Rostock». Iniciada la ejecución del contrato, el comprador vendió las mercancías a una sociedad belga, la cual, a su vez, las envió a un fabricante portugués. Este último, descu-

83 «Les dispositions de la convention et ses principes généraux, réunis à l'heure actuelle dans les Principes d'UNIDROIT relatifs aux contrats du commerce international, son parfaitement adaptés à la résolution du litige». 
brió defectos en los bienes adquiridos y vendidos y rechazó toda entrega ulterior. Una vez recibida la denuncia del defecto de conformidad, el vendedor austriaco rechazó pagar los daños, sosteniendo que la reclamación no había sido cursada inmediatamente. El comprador alemán emprendió el procedimiento arbitral. El primer laudo concluyó con la condena del vendedor al resarcimiento de daños, el segundo laudo con la condena del comprador. En ambos casos, el árbitro se encontró con tener que afrontar la misma cuestión, es decir, la fijación del tipo de interés.

a) En el laudo n. SCH-4318, de 15 de junio de 1994, el comprador se dirigió al árbitro aduciendo el incumplimiento por parte del vendedor por defectos de la mercancía vendida (16). Por su parte, el vendedor alegó que la acción del comprador había prescrito de acuerdo con los plazos previstos en el contrato.

El árbitro único comprobó la aplicabilidad al caso de la CV. Posteriormente, con fundamento en la Convención, condenó al vendedor austriaco al resarcimiento de los daños, calculados a partir del día de la demanda del comprador. A efectos de la cuantificación de los daños, el árbitro observó que el art. 78 de la CV no resolvía la cuestión del tipo de interés aplicable. La CV, de hecho, nada dispone en relación con esta cuestión, dejando abierto el problema de cubrir la laguna en base a los principios generales previstos en la convención misma, según su art. 7, 2. Dado que uno de los principios generales de la Convención está constituido por la obligatoriedad del resarcimiento íntegro de los daños (art. 74 de la CV), el árbitro decidió referirse al tipo bancario aplicado en el país de acreedor con referencia a la moneda de pago, encontrando su fundamento en el art. 7. 4. 9, pár. $2^{\circ}{ }^{\circ}$, de los Principios UNIDROIT. Esta decisión se fundamentaba en la consideración según la cual el acreedor de una suma de dinero, caso de incumplimiento o demora del deudor, debía dirigirse a su propio banco, que le concedería un crédito equivalente en moneda local u otra moneda al tipo de interés practicado en el Estado en el que está domiciliado. Por tanto, el tipo de interés aplicable se determinaba en base al tipo medio relativo al dólar estadounidense vigente en Alemania durante el periodo considerado.

b) También en el laudo n. ${ }^{\circ} \mathrm{SCH}-4366$, de igual fecha de 15 de junio de 1994, la controversia tenía su origen en un contrato de suministro de chapa. El contenido de la controversia resultaba similar a lo expuesto anteriormente, sin embargo la cuestión que se le presentaba al árbitro era en parte distinta.

En este caso, en efecto, el árbitro apreció que la mercancía había sido entregada de conformidad con la norma del art. $53 \mathrm{CV}$ y, por lo tanto, el comprador debía pagar el precio a partir de la recepción de las facturas, 
según lo establecido en el contrato (art. 58, párrafo $1 .^{\circ}$, de la $\mathrm{CV}$ ). Al condenar al comprador alemán al resarcimiento de daños, el árbitro apuntó, también en este caso, que la CV nada disponía en materia de tipo de interés aplicable a la suma debida en concepto de resarcimiento de daños y, además, laguna que debía ser cubierta a través de los principios generales a que hace referencia el art. 7, párrafo $2 .^{\circ}$, de la CV. La solución, por lo tanto, no se encontró a través de la técnica tradicional de la localización de la relación, sino mediante la aplicación del art. 7.4.9 de los Principios UNIDROIT. Por consiguiente, el tipo de interés aplicable se encontró en el average prime rate sobre el dólar estadounidense y el marco alemán vigente en Austria durante el periodo considerado.

2) Otras aplicaciones de los Principios UNIDROIT, en función interpretativo-integrativa de la $\mathrm{CV}$, se produjeron en los laudos dictados por la Cámara de Comercio e Industria de la Federación de Rusia. Dichos laudos fueron dictados a propósito de problemas producidos en supuestos de compraventa internacional, y los Principios UNIDROIT resultaron aplicados con el fin de establecer la imputabilidad parcial de los daños al perjudicado, ex art. 7.4.7, además de en materia de interpretación del contrato estipulado entre un comprador ruso y un vendedor británico.

3) En un laudo dictado el 1 de diciembre de 1996, en el marco de un arbitraje desarrollado ante la Cámara Arbitral Nacional e Internacional de Milán, se aplicaron los Principios UNIDROIT a un contrato de agencia entre una sociedad italiana y otra norteamericana que desarrollaba los servicios de agencia comercial.

El principal sostuvo la resolución del contrato por incumplimiento del agente, mientras que este último reclamó el resarcimiento de daños aduciendo la falta de causa de la resolución del contrato. Las partes obtuvieron un acuerdo según el cual serían de aplicación los Principios UNIDROIT en el marco de un arbitraje de equidad. Por tanto, el árbitro se fundamento en el art. 1.3 que sanciona el carácter vinculante del contrato. A continuación, el árbitro trajo a colación el art. 4 . 1 y el art. 4.2, relativos ambos a la interpretación del contrato, al objeto de determinar la legitimidad de la resolución. Por otro lado, con base en el art. 7.3.1. y en el art. 7.3.5, ordenó al agente la devolución de las mercancías propiedad del principal, e impuso a este último el pago de las comisiones correspondientes a las transacciones impulsadas por el agente. El árbitro se sirvió, asimismo, del art. 7, párrafos 1, 2, 3 y 4, para fundamentar el derecho del agente a la percepción de una indemnización por incumplimiento de contrato del principal. 
A modo de conclusión, procede la cita del antiguo brocardo, según el cual electa una via non datur recursus ad alteram.

La belleza del sistema conflictual reside en la precisión y en el refinamiento con que las técnicas de localización permiten la definición de las normas que han de ser de aplicación y de aquellas otras que hubieren de ser excluidas. Sin embargo, todo da la impresión de que la técnica conflictual clásica tiene necesidad del soplo renovador aportado por la lex mercatoria y por los principios generales que, paulatinamente, van siendo definidos en lo atinente a las relaciones mercantiles internacionales.

Ad contrarium, ello no permite la evocación meramente simbólica de los principios jurídicos generales actualmente en fase de preparación y definición, de índole regional o universal, que parecen apuntar que las regiones y el universo buscan, más o menos a tientas, un derecho de obligaciones y contratos material, substancial, y compartido. 